\title{
The effects of maternal SSRI exposure on the serotonin system, prefrontal protein expression and behavioral development in male and female offspring rats
}

\section{Mo Xian Chen}

Kunming Medical University

\section{Shu Cheng}

china resources WISCO general hospital

\section{Lei Lei}

Southern Medical University Nanfang Hospital

\section{Chloe U Wallis}

medical sciences division, university of oxfors

Qiang Liu

the chinese university of hong kong

\section{Aijin Lin}

Kunming Medical University

\section{Xiaofan Zhang}

Tongji Hospital of Tongji Medical College of Huazhong University of Science and Technology

\section{Michael James Lukowicz}

University of Notre Dame

\section{Pak C Sham}

University of Hong Kong

Qi Li ( $D$ liqi@hku.hk)

https://orcid.org/0000-0002-3732-2578

\section{Lijuan Ao}

Kunming Medical University

\section{Research}

Keywords: SSRI, 5-HT, SERT, TPH, NAA/Cr, Proteomics, Prefrontal cortex

Posted Date: February 3rd, 2020

DOl: https://doi.org/10.21203/rs.2.22439/v1 
License: (c) (i) This work is licensed under a Creative Commons Attribution 4.0 International License. Read Full License

Version of Record: A version of this preprint was published at Neurochemistry International on June 1st, 2021. See the published version at https://doi.org/10.1016/j.neuint.2021.105041. 


\section{Abstract}

\section{Background}

Prenatal exposure to selective serotonin reuptake inhibitor (SSRI), such as fluoxetine (FLX) may increase susceptibility to autism spectrum disorder (ASD). However, findings from published studies on SSRI and ASD are inconsistent. The use of a rodent model can provide a clear indication as to whether prenatal exposure to SSRIs, independent of maternal psychiatric disorders or genetic syndromes, can cause longterm behavioral and ASD-related neurobiological abnormalities in offspring.

Methods

FLX or normal saline (NS) was administered to pregnant Sprague-Dawley (SD) rats (FLX=30, NS=27) on gestation day 11 till birth. The resulting offspring were assessed in terms of their physical development and behavior, and underwent in vivo magnetic resonance spectroscopy (MRS) to quantify biochemical alterations in the prefrontal cortex (PFC). Ex vivo measurements of brain serotonin level and a proteomic analysis were also undertaken.

Results

The offspring (male offspring in particular) of fluoxetine exposed mothers showed delayed physical development, increased anxiety and impaired social interaction. Moreover, down-regulation of 5-HT or SERT expression and up-regulation of TPH levels was observed in the PFC. We also found that prenatal FLX exposure significantly decreased NAA/tCr with $1 \mathrm{H}-\mathrm{MRS}$ in the PFC. Finally, a proteomic study revealed sex-dependent differential protein expression.

\section{Conclusions}

These findings may have translational importance suggesting that the use of SSRI medication alone in pregnant mothers may result in developmental delay and autistic-like behavior in their offspring. Our results also help to guide the choice of outcome measures in the identification of molecular and developmental mechanisms that may confer vulnerability in ASD.

\section{Background}

Depression is a highly prevalent psychiatric disorder, especially in the perinatal period ${ }^{[1]}$, during which global estimate of prevalence of perinatal depression is $11.9 \%$ in women ${ }^{[2,3]}$. It has recently been suggested that $7-8 \%$ of pregnant women receive antidepressants ${ }^{[4]}$, the most prescribed of which are selective serotonin reuptake inhibitors (SSRIs) which target the serotonin transporter (5-HTT) and increase extra-neuronal serotonin $(5-\mathrm{HT})$ levels. Prenatal exposure to SSRIs in utero has an ascribed association with low birth weight, preterm birth ${ }^{[5]}$ and congenital malformation ${ }^{[6]}$ as well as long-term neuropsychological sequelae, such as depression, anxiety and social dysfunction ${ }^{[7]}$, that persist into 
adulthood $^{[8-10]}$. There is a growing body of evidence suggesting there may be an association between the use of SSRIs in pregnancy and the risk of autism spectrum disorder (ASD) in children ${ }^{[11-17]}$. However, recent systematic reviews have reported that when controlling for maternal psychiatric conditions and other confounding factors (including genetic syndromes and congenital anomalies which are associated with autistic like behavior) there is insufficient evidence for a significant association between SSRI use during pregnancy and ASD in the offspring ${ }^{[18-20]}$. By removing these confounding factors, animal studies can provide a clearer indication as to whether prenatal exposure to SSRIs, independent of maternal psychiatric disorders or genetic syndromes, can cause long-term behavioral and ASD-related neurobiological abnormalities in offspring.

5-HT is a key regulator of the neurodevelopment, acting in processes such as cell migration, axon growth, synaptogenesis, circuit wiring and neurogenesis ${ }^{[21-24]}$. Disruption of $5-\mathrm{HT}$ signaling during specific periods in brain development may be associated with a series of neuropsychiatric illnesses, including autism $^{[25-27]}$, attention deficit hyperactivity disorder $(A D H D)^{[28]}$, depression ${ }^{[29]}$ and anxiety ${ }^{[30]}$ in humans. This is thought to occur throughout the alteration of key processes in neurodevelopment which are modulated by $5-\mathrm{HT}^{[31]}$. Therefore, since SSRIs can cross the placenta and reach the fetal brain, it may be expected that fetal exposure to SSRIs might have long-term neurobehavioral and neurodevelopmental consequences. Thus, the present study was designed to test the hypothesis that disruption of $5-\mathrm{HT}$ system during prenatal neurodevelopment by maternal exposure to SSRIs may contribute to the physical changes, altered motor function, and behavioral abnormalities relevant to ASD in offspring. To test the postnatal consequences of exposure to an early antidepressant insult, we used the common SSRI fluoxetine (FLX), in rats during the embryonic period (E11-E21), a sensitive period for serotonergic neuron differentiation and migration ${ }^{[32]}$. In vivo, the Raphe nuclei are the primary site of serotonin production. Whilst the prefrontal cortex is also a region of interest due to its role in the core symptoms of ASD, including executive function deficits and maladjusted social and emotional responses ${ }^{[33,34]}$. Therefore we further investigated the influence of prenatal FLX exposure on levels of 5-HT, tryptophan hydroxylase (TPH) and serotonin reuptake transporter (SERT) in both the raphe nuclei and the prefrontal cortex, to investigate the mechanisms underlying the regulation of serotonin synthesis and reuptake at different developmental stages of the offspring.

Previous studies of prenatal exposure to SSRIs in rodent models of ASD, have focused mainly on ex vivo measurements of biochemical changes, rather than in vivo testing. The use of proton magnetic resonance spectroscopy ( $\left.{ }^{1} \mathrm{H}-\mathrm{MRS}\right)$, however, enables non-invasive assessment of certain metabolites in the brains of living animals. MRS studies have revealed a reduction in levels of $\mathrm{N}$ acetylaspartate/creatine (NAA/Cr) in the brains of ASD individuals ${ }^{[35,36]}$. However, it is not known whether prenatal exposure to SSRIs is a risk factor for such changes. Therefore, we wished to demonstrate whether in vivo changes in brain metabolites similar to those reported in the clinical conditions, are caused by prenatal FLX exposure. 
The present work also uses proteomics, a powerful tool to undercover pathological mechanisms at the molecular level. Most previous proteomics studies on ASD have used blood or other peripheral tissue, only few studies have used brain tissue. Again, the underlying molecular mechanisms relating to abnormal brain development in SSRI-exposed offspring are unknown.

Therefore, in this study, first we systematically assess developmental milestones, such as body weight, eye opening and neurological reflexes, from postnatal days (PND) 1 to 21 in rats offspring exposed to either FLX or saline in prenatal life. The core behaviors of locomotor activity, anxiety and social interaction were also examined in the young rats. Secondly, we used in vivo MRS to quantify biochemical alterations in the mPFC of young adult rats. Finally, we measured the ex vivo level of 5-HT, TPH and SERT in the prefrontal cortex and raphe nucleus at PND 7 and 35. Proteomics analysis of the prefrontal cortex was applied at PND 35, coupled with western blot confirmation of selected proteins.

\section{Methods}

\section{Prenatal treatment}

Male and female Sprague-Dawley rats (220-250 g, 70-100d) were mated overnight and gestational day 0 (GD 0) was determined through vaginal smear and the presence of spermatozoids. From GD 11 until birth (PND 1), pregnant dams were intraperitoneally (IP) injected daily with $12 \mathrm{mg} / \mathrm{kg}$ of fluoxetine ${ }^{[37]}$ (FLX, Patheon France) as the experimental group while the control group was injected with equal volumes of normal saline (NS).

Animals

All offspring were maintained on a $12 \mathrm{~h} \mathrm{light/dark} \mathrm{cycle} \mathrm{(light} \mathrm{from} 7$ a.m. to 7 p.m.) at constant room temperature $\left(23-25^{\circ} \mathrm{C}\right)$ and humidity $(60 \%)$ with free access to food and water. The numbers of pregnant rats from the FLX and NS groups were 30 and 27 respectively, these were generated from 3 different batches. Male and female offspring were examined for general physical development including body weight, eye opening, incisor eruption, surface righting reflex and cliff avoidance, from PND 1 to $21^{[38,39]}$. The free suspension test was performed every other day during PND 12-20[39]. Animals were weaned on PND 21 and kept in same-sex cages ( 5 rats/cage). The offspring then underwent a battery of behavioral tests including the buried food pellet test, open field and social ability test. The timeline of the experiment, the batches and number of animals used in all the experiments including behavioral tests, MRS, 5-HT assay, western blot, and proteomics are described in Fig. 1 and Table 1 respectively. All experiments were performed in accordance with the Animal Experimentation Ethics Committee at the Kunming Medical University. 
Table 1

Sample size, batch and age of rats for in vivo and ex vivo experiments and the sequence of different experiments

\begin{tabular}{|c|c|c|c|c|c|c|c|c|}
\hline \multicolumn{2}{|c|}{ In vivo Experiments } & \multicolumn{2}{|l|}{ NS } & \multicolumn{2}{|l|}{ FLX } & $\begin{array}{l}\text { Age at } \\
\text { Testing (PND) }\end{array}$ & \multicolumn{2}{|c|}{ Batch } \\
\hline \multirow[t]{3}{*}{$\begin{array}{l}\text { Physical } \\
\text { development }\end{array}$} & $\begin{array}{l}\text { Body } \\
\text { weight }\end{array}$ & \multicolumn{2}{|c|}{ 14区, 13囚 } & \multicolumn{2}{|c|}{ 13区, 14区 } & $1,4,7,10,14,17,21$ & \multicolumn{2}{|l|}{$A$} \\
\hline & Eye opening & \multicolumn{2}{|c|}{ 13凶, 13凶 } & \multicolumn{2}{|c|}{ 13区, 14区 } & $14-16$ & \multicolumn{2}{|l|}{ A } \\
\hline & $\begin{array}{l}\text { Incisor } \\
\text { eruption }\end{array}$ & \multicolumn{2}{|c|}{ 14区, 13区 } & \multicolumn{2}{|c|}{ 14区, 13囚 } & $11-14$ & \multicolumn{2}{|l|}{ A } \\
\hline \multirow[t]{2}{*}{$\begin{array}{l}\text { Neurological } \\
\text { reflexes }\end{array}$} & $\begin{array}{l}\text { Righting } \\
\text { reflex }\end{array}$ & \multicolumn{2}{|c|}{$11 \otimes, 13 \rrbracket$} & \multicolumn{2}{|c|}{$8 \rrbracket, 14 \rrbracket$} & $3-7$ & \multicolumn{2}{|l|}{ A } \\
\hline & $\begin{array}{l}\text { Cliff } \\
\text { avoidance }\end{array}$ & \multicolumn{2}{|c|}{$14 \rrbracket, 13 \rrbracket$} & \multicolumn{2}{|c|}{$13 \rrbracket, 14 \rrbracket$} & $4-7$ & \multicolumn{2}{|l|}{ A } \\
\hline \multirow[t]{4}{*}{$\begin{array}{l}\text { Core } \\
\text { behavior }\end{array}$} & $\begin{array}{l}\text { Suspension } \\
\text { test }\end{array}$ & \multicolumn{2}{|c|}{ 14区, 13凶 } & \multicolumn{2}{|c|}{ 13区, 14『 } & $12,14,16,18,20$ & \multicolumn{2}{|l|}{ A } \\
\hline & $\begin{array}{l}\text { Buffed food } \\
\text { pellet test }\end{array}$ & \multicolumn{2}{|c|}{$14 \rrbracket, 13 \rrbracket$} & \multicolumn{2}{|c|}{$13 \rrbracket, 14 \rrbracket$} & 27 & \multicolumn{2}{|l|}{ A } \\
\hline & Open field & \multicolumn{2}{|c|}{$14 \rrbracket, 12 \rrbracket$} & \multicolumn{2}{|c|}{ 13凶, 13凶 } & $28-30$ & \multicolumn{2}{|l|}{$A$} \\
\hline & $\begin{array}{l}\text { Sociability } \\
\text { test }\end{array}$ & \multicolumn{2}{|c|}{ 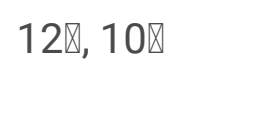 } & \multicolumn{2}{|c|}{ 10区, 10区 } & $33-35$ & \multicolumn{2}{|l|}{ A } \\
\hline \multirow{2}{*}{\multicolumn{2}{|c|}{ Brain metabolites (MRS) }} & PFC & RPN & PFC & RPN & 35 & \multirow{2}{*}{\multicolumn{2}{|c|}{ C }} \\
\hline & & $4 \rrbracket, 4 \rrbracket$ & $\begin{array}{l}4 \rrbracket, \\
4 \rrbracket\end{array}$ & $4 \rrbracket, 4 \rrbracket$ & $4 \rrbracket, 4 \rrbracket$ & & & \\
\hline Ex vivo Experir & ents & NS & & FLX & & Age at Testing $(P$ & & Batch \\
\hline ELISA for $5-\mathrm{HT}$ & & PFC & RPN & PFC & RPN & 35 & & A \\
\hline & & $\begin{array}{l}3 \rrbracket \\
3 \rrbracket\end{array}$ & $\begin{array}{l}3 \rrbracket \\
3 \rrbracket\end{array}$ & $\begin{array}{l}3 \rrbracket \\
3 \rrbracket\end{array}$ & $3 \rrbracket, 3 \rrbracket$ & & & \\
\hline Western blot $\mathrm{fc}$ & r SERT and & PFC & RPN & PFC & RPN & 7 & & $A, B, C$ \\
\hline & & $\begin{array}{l}\text { 7区, } \\
6 \rrbracket\end{array}$ & $\begin{array}{l}7 \rrbracket \\
6 \rrbracket\end{array}$ & $\begin{array}{l}6 \rrbracket \\
8 \rrbracket\end{array}$ & 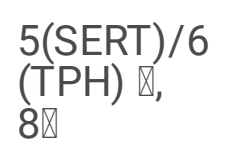 & & & \\
\hline
\end{tabular}




\begin{tabular}{|c|c|c|c|c|c|c|}
\hline In vivo Experiments & NS & & FLX & & $\begin{array}{l}\text { Age at } \\
\text { Testing (PND) }\end{array}$ & Batch \\
\hline & PFC & RPN & PFC & RPN & \multirow[t]{2}{*}{35} & \\
\hline & $\begin{array}{l}\text { 7】, } \\
4 \rrbracket\end{array}$ & $\begin{array}{l}7 \bigotimes, \\
4 \bigotimes\end{array}$ & $\begin{array}{l}5 \rrbracket \\
3 \rrbracket\end{array}$ & 5区, 3® & & \\
\hline \multirow[t]{2}{*}{ IF for SERT and TPH } & PFC & RPN & PFC & RPN & \multirow[t]{2}{*}{35} & \multirow[t]{2}{*}{$A, B$} \\
\hline & $\begin{array}{l}3 \rrbracket \\
3 \rrbracket\end{array}$ & $\begin{array}{l}3 \rrbracket \\
3 \rrbracket\end{array}$ & $\begin{array}{l}3 \rrbracket \\
3 \rrbracket\end{array}$ & $3 \rrbracket, 3 \rrbracket$ & & \\
\hline \multirow[t]{2}{*}{ Proteomics } & PFC & & PFC & & \multirow[t]{2}{*}{35} & \multirow[t]{2}{*}{ A } \\
\hline & $3 \rrbracket, 3 \rrbracket$ & & $3 \rrbracket, 3 \rrbracket$ & & & \\
\hline
\end{tabular}

General Physical Development And Neurological Reflex

All pups alive at the time were examined for general physical development, including body weight at PND $1,4,7,10,14,17$ and 21 , eye opening at PND 14-16, and incisor eruption at PND 11-14 ${ }^{[39]}$.

In addition, neurological reflexes such as the surface righting reflex (PND 3-7) and cliff avoidance (PND $4-7)$ were measured. The righting reflex ${ }^{[40]}$ was assessed by measuring the ability to turn ventrally within $30 \mathrm{~s}$ after being placed in a dorsal position. Pups were scored 1 if they could turn within $30 \mathrm{~s}$. Otherwise, they scored 0 . Cliff avoidance was measured according to the Altman and Sudarshan ${ }^{[41]}$ method. The pup was placed on a table with its nose and forepaws just over the edge. The reflex was considered to be formed if the pup crawled away from the edge within $10 \mathrm{~s}$, in which case they scored 1 . Otherwise, they scored 0 .

Behavioral Tests

Suspension test

At PND 12, 14, 16, 18 and 20, the pups neuromotor function was measured using the suspension test ${ }^{\text {[39] }}$. The forepaws of the rat were placed on a homemade T-type fixed horizontal metal cross bar $(0.5 \mathrm{~cm} \mathrm{D} \times$ $30 \mathrm{~cm} \mathrm{H}$ ). The experimenter loosen their hand when the rat held the bar, meanwhile, started to record the suspension time.

Buried food pellet test

A modified version of the buried food pellet test was carried out at PND 27, using an exogenously scented pellet ${ }^{[42,43]}$. Before the test, the rats were familiarized with the experimental facility, by being placed in the plastic test cage $(45 \times 24 \times 20 \mathrm{~cm})$ for 10 min daily over the 3 days prior to trials. Rats from the NS and 
FLX groups were given a food-restricted diet $(0.5 \mathrm{~g}$ chow/rat/24 h) for 1 day before testing. They still had free access to water. In the test, a rat was placed randomly in the test cage where a $1 \mathrm{~g}$ food pellet was buried $0.5 \mathrm{~cm}$ below the surface of a $3 \mathrm{~cm}$ deep layer of bedding materials. The location of the pellet was changed daily at random. The latency to find the food pellet was recorded and defined as the time between placement of the rat in the cage and discovery of the food pellet by grasping it with its forepaws or teeth. Each experimental rat was allowed to consume the pellet and then returned to its cage after the test. Rats that did not find the food pellet within 5 min were removed and placed back into their home cage (regarded as 5 minutes latency for the analysis). The bedding material in the test cage was changed between trials ${ }^{[44]}$.

Open field test (OFT)

The open field test was implemented at PND 28-30 and followed methods previously published ${ }^{\text {[45] }}$. The apparatus, constructed of plywood and painted black, consisted of a $100 \mathrm{~cm} \mathrm{~L} \times 100 \mathrm{~cm} \mathrm{~W} \times 50 \mathrm{~cm} \mathrm{H}$ area and had a defined central area $(50 \mathrm{~cm} \mathrm{~L} \times 50 \mathrm{~cm} \mathrm{~W})$ and periphery. All animals were tested between 9:00 a.m. and 6:00 p.m. At the beginning, the rats were gently placed in the center of the open field and allowed to explore undisturbed for $5 \mathrm{~min}$. No observers were present in the room during the testing. The duration of time spent in the central area and total distance traveled in the field were analyzed by using a Smart 3.0 tracking system. The apparatus was wiped with water and dried with tissues after each trail. Social ability test

The social ability test was adapted from Nadler ${ }^{[46]}$, and was performed on offspring at PND 33-35. A 3chamber apparatus $(60 \times 22 \times 40 \mathrm{~cm})$ made from polycarbonate was used. It contained two removable partitions $(22 \times 40 \mathrm{~cm})$ separating it into three equal chambers, with a square opening $(10.5 \times 5.5 \mathrm{~cm})$ on each removable partition allows rats to move cross the chambers. One wire cage $(10 \times 15 \mathrm{~cm})$ was put into each side chambers of the apparatus. Before the test, partitions of each side were removed, the experimental rat was placed into the middle chamber for $5 \mathrm{~min}$ and allowed to explore. We observed no difference in the preference for the either side chamber. After $5 \mathrm{~min}$ habituation period, one unfamiliar and contemporary SD rat was placed in one of the wire cages in one of the side chambers. And then, both of the removable partitions were opened to allow the test subject to explore the three chambers freely, for $10 \mathrm{~min}$. The position of the strange rat was changed randomly between left and right side chambers between trials. The distances rat moved in each chamber and the entries into each side chamber were analyzed by using a Smart3.0 tracking system. The apparatus was wiped with water and dried with tissue after each trail.

Western Blot

Brain samples were collected from the NS- and FLX-exposed rats. The prefrontal cortex and raphe nuclei were dissected over ice and quickly stored at $-80^{\circ} \mathrm{C}$ until they were processed. Brain tissues were homogenized by sonication in a RIPA lysis buffer containing protease and phosphatase inhibitor cocktails. The supernatant was collected after centrifugation at $12000 \mathrm{rpm}$ for $20 \mathrm{~min}$ at $4{ }^{\circ} \mathrm{C}$. The concentration of protein was quantified by a bicinchoninic acid assay (BCA kit, Thermo scientific) and all the samples were equalized to $20 \mu \mathrm{g}$. Procedures for western blot followed those described previously ${ }^{[47}$, 
48]. The primary antibodies to the following proteins: anti- $\beta$-actin (1:1000, SANTACRUZ, SC-47778), antiSERT (1:2000, Abcam, ab181034), anti-TPH (1:500, Abcam, ab52954) were incubated with the membrane in the antibody dilution buffer with gentle agitation overnight at $4{ }^{\circ} \mathrm{C}$, then incubated with the secondary antibody (1:2000 dilution, P044801, Dako, Glostrup, Denmark) for $1 \mathrm{~h}$ at room temperature. The signal was revealed by chemiluminescent detection method (ECL, Amersham, Buckinghamshire, UK). Finally, protein bands were analyzed and quantified using the gel image processing system Image $\mathrm{J}$, and normalized with $\beta$-actin concentrations.

\section{Immunofluorescence}

Rats were sacrificed after anesthesia with $5 \%$ chloral hydrate via intraperitoneal injection and then perfused with $4 \%$ paraformaldehyde. The brains were extracted and put into $15 \%$ and then $30 \%$ sucrose solution successively until the brains sank to the bottom. The brains were then embedded in Optimal Cutting Temperature compound (OCT) and stored at $-80^{\circ} \mathrm{C}$. After this, a frozen section machine was used to cut brains into coronal slices of $10 \mu \mathrm{m}$ thickness (including the prefrontal cortex and raphe nuclei) before being stored at $-20^{\circ} \mathrm{C}$. Identification of brain areas was carried out according to Paxinos and Watson rat brain atlas ${ }^{[49]}$. Slices were washed and then blocked using goat serum for $2 \mathrm{~h}$ at room temperature. Afterwards, they were incubated with primary antibody (1:1000, anti-NeuN, Abcam Company, ab104224; 1:1000, anti-SERT, Abcam Company, ab44520; 1:50, anti-TPH, ab52954, Abcam Company) overnight at $4{ }^{\circ} \mathrm{C}$ in a humidified container. Slices then were incubated with secondary antibody (Goat Anti-Mouse IgG labeled with FITC Fluorescein, Proteintech; Goat Anti-Rabbit IgG labeled with Cy3 Fluorescein, Proteintech) on a shaker at room temperature for $2 \mathrm{~h}$ in dark room. Slices were washed and then were cover slipped with Prolong Gold with DAPI (P36931, Invitrogen, CA, USA). Slides were subsequently imaged on a fluorescence microscope.

Assay of 5-HT in the prefrontal cortex and raphe nucleus

Sandwich enzyme-linked-immunosorbent assay (ELISA) was used to detect the protein level of 5-HT in the prefrontal cortex and raphe nuclei in the NS and FLX groups at PND 35. At PND 35, rats were rapidly sacrificed after anesthesia with chloral hydrate via intraperitoneal injection. The prefrontal cortex and raphe nuclei were dissected over ice using a rat brain matrix and immediately stored at $-80^{\circ} \mathrm{C}$ until use. Samples were weighed and placed into a lysis buffer (RIPA) and homogenized. Then, samples were centrifuged at $12000 \mathrm{rpm}$ for $20 \mathrm{~min}$ and the supernatants were collected and frozen at $-80^{\circ} \mathrm{C}$ until assays were conducted. 5-HT level was measured using the rat 5-HT ELISA kit (Bio-Swamp Life science) in accordance with the manufacturer's instructions. Samples and standards were duplicated and run in the same assay.

${ }^{1}$ H-MRS acquisition

In vivo ${ }^{1} \mathrm{H}-\mathrm{MRS}$ experiments were performed on a $7 \mathrm{~T} / 20 \mathrm{~cm}$ Bruker Biospec scanner (Ettlingen, Germany) $[50,51]$, with a $72 \mathrm{~mm}$-diameter linear transmitter coil for excitation and a $40 \mathrm{~mm}$-diameter coil for signal 
reception. Animals were anaesthetized during scanning with a $3 \%$ isoflurane/air mixture. T2-weighted scout images were acquired with a two-dimensional rapid acquisition with a relaxation enhancement (RARE) sequence (repetition time/echo time $=2000 / 36 \mathrm{~ms}$, RARE factor $=8$, field of view $(F O V)=3 \mathrm{~cm} \times$ $3 \mathrm{~cm}$, matrix size $=256 \times 256$, slice thickness $=0.8 \mathrm{~mm}$ ) to localize voxels of interest for in vivo ${ }^{1} \mathrm{H}$-MRS. Single-voxel spectra were acquired sequentially from the medial prefrontal cortex (voxel size: $2 \times 2.5 \times 2.4$ $\mathrm{mm}^{3}$ ) using a spectroscopy sequence (repetition time/echo time $=2500 / 20 \mathrm{~ms}$, spectral bandwidth $=$ $4 \mathrm{kHz}, 2048$ data points, and 512 averages). The voxel used was necessarily larger than the actual rat medial prefrontal cortex, but the majority of the scanned volume was medial prefrontal cortex. First- and second-order localized shimming was performed automatically with the FieldMap protocol provided by the Bruker console, resulting in an average full-width at a half maximum linewidth with a water signal $\leq$ $10 \mathrm{~Hz}$. To acquire a spectra of metabolites, the water signal was suppressed by VAPOR (variable power radiofrequency pulses with optimized relaxation delays).

${ }^{1}$ H-MRS spectral analysis

The MR spectra were processed using the LCModel software (LCModel Version 6.3-1A; Stephen Provencher, Oakville, ON, Canada) to quantify the metabolite contents ${ }^{[11]}$. No extra data processing steps were employed other than those incorporated inside LCModel. The signals within the chemical shift ranged from 0.5 to 4.5 p.p.m. and were fitted as a superposition of a set of the in vitro basis spectra provided by the LCModel package using a constrained regularization algorithm. The lipid and macromolecule signals were simulated automatically by LCModel and decayed rapidly. The time-domain model functions of metabolites, including total choline (tCho), total creatine $(\mathrm{tCr}$ ) and $\mathrm{N}$-acetylaspartate (NAA) were estimated in the medial prefrontal cortex and raphe nucleus ${ }^{[52]}$. Only the results that fit with a Cramér-Rao lower bound of $15 \%$ were reported and kept for further analysis. For each spectrum, the level of total creatine $(\mathrm{tCr})$ was used as the internal reference to quantify other metabolites. Group differences in $\mathrm{NAA} / \mathrm{tCr}, \mathrm{tCho} / \mathrm{tCr}$ ratios were analyzed.

\section{Proteomics}

Three male and three female rats from each of the NS and FLX groups were rapidly sacrificed after anesthesia with chloral hydrate via intraperitoneal injection at PND 35. The prefrontal cortex was dissected over ice and immediately stored at $-80^{\circ} \mathrm{C}$. It was then homogenized in $2 \mathrm{D}$ lysis buffer ${ }^{[53,54]}(7 \mathrm{M}$ Urea, 2M Thiourea, $10 \mathrm{mmol}$ DTT, 2\% CHAPS, 0.5\% IPG buffer) for $30 \mathrm{~s}$ and centrifuged at $12000 \mathrm{rpm}$ for $20 \mathrm{~min}$ to remove cell debris. Supernatant for 2-DE was collected, and the proteins were separated by twodimensional polyacrylamide gel electrophoresis (PAGE). Following this, the protein spots were visualized by silver staining. Afterwards, the proteins were digested with trypsin. The peptide extracts and the supernatant of the gel spot were combined and then completely dried.

The resulting peptides were extracted and analyzed by mass spectrometry (MS). Samples were resuspended with $5 \mu \mathrm{L} 0.1 \%$ TFA followed by mixing in a 1:1 ratio with a matrix consisting of a saturated solution of a-cyano-4-hydroxy-trans-cinnamic acid in $50 \%$ ACN, $0.1 \%$ TFA. Then $1 \mu \mathrm{L}$ of this mixture was 
spotted on a stainless-steel sample target plate. Peptide MS and MS/MS were performed on an ABI 5800 MALDI-TOF/TOF Plus mass spectrometer (Applied Biosystems, Foster City, USA). Data were acquired in a positive MS reflector using a CalMix5 standard to calibrate the instrument (ABI5800 Calibration Mixture). Afterwards, both the MS and MS/MS data were integrated and processed using the GPS Explorer V3.6 software (Applied Biosystems, USA) with default parameters. Based on combined MS and MS/MS spectra, proteins were successfully identified based on $95 \%$ or higher confidence interval of their scores in the MASCOT V2.3 search engine (Matrix Science Ltd., London, U.K.). The samples of the prefrontal cortex were collected from prenatal NS or FLX-exposed rats for western blot validation (primary antibody: 1:2000, anti-14-3-3 gamma, Abcam Company, ab137048; 1:10000, anti-CRMP3, Abcam Company, ab128875; 1:1000, anti-peroxiredoxin 3, Abcam Company, ab73349). The western blot procedures were the same as described above.

Statistical analysis

All statistics were carried out using SPSS software version 23 (SPSS Inc, USA). There are sex differences in most of the experiments, so all results are presented by sex. Repeated measures analysis of variance were carried out on the general physical development, neurological reflex and social ability tests, whilst the buried food pellet test and open field test were analyzed with a 2 (groups (FLX, or NS)) $\times 2$ (sex (male or female)) general linear model (GLM). Bonferroni was performed for post hoc comparisons to determine differences between and within-subject. The protein levels of 5-HT and the MRS results were analyzed using GLM and Bonferroni post hoc comparison. The western blot validation of proteomics was analyzed using an independent sample $T$ test. The threshold for statistical significance was $p<0.05$.

\section{Results}

1 General physical development

\subsection{Body weight}

First, data were combined across sex for analysis. There was a significant main effect of time $\left[F_{(6,50)}=\right.$ 712. 84, $p<0.01]$, group $\left[F_{(1,50)}=96.93, p<0.01\right]$ and $\operatorname{sex}\left[F_{(1,50)}=4.29, p=0.044\right]$. As expected, the weight increased over the course of experiment. However, the FLX-exposed rats show significantly reduced body weight compared to the control group. The dataset was split by sex for further analysis.

In male offspring, there was a significant main effect of time $\left[F_{(6,20)}=405.03, p<0.01\right]$, group $\left[F_{(1,25)}=\right.$ $40.51, p<0.01]$ and an interaction between group and time $\left[F_{(6,20)}=8.64, p<0.01\right]$. On post hoc comparisons, the body weight of the FLX group was lighter than the control group at PND $1,4,7,10,14,17$ and $21(p<0.01)$ (Fig. 2A).

In female offspring, there was a significant main effect of time $\left[F_{(6,20)}=313.69, p<0.01\right]$, group $\left[F_{(1,25)}=\right.$ $58.01, p<0.01]$ and an interaction between group and time $\left[F_{(6,20)}=13.10, p<0.01\right]$. Post hoc 
comparisons confirmed that body weight of the FLX-exposed rats was lighter than the control rats between PND 1 and 21 ( $p<0.01$ ) (Fig. 2B).

\subsection{Eye Opening}

All offspring began to open their eyes at PND 15 and all were completely open at PND 16. There was a significant main effect of time $\left[F_{(4,49)}=270.86, p<0.01\right]$, indicating as expected, that eye opening became more visible over time. However, there was no main effect of group or sex and no significant interaction of group $\times$ sex or time $\times$ sex.

\subsection{Eruption Of Incisors}

Eruption of incisors occured at PND 12 and completed at PND 14. Again, there was a significant main effect of time $\left[F_{(3,50)}=136.13, p<0.01\right]$, indicating eruption of incisors became more visible over time. However, there was no main effect of group or sex and no significant interaction of group $\times$ sex or time $\times$ sex.

2. Neurological Reflexes

\subsection{Righting reflex}

There was a significant main effect of time $\left[F_{(4,42)}=3.81, p=0.005\right]$ and group $\left[F_{(1,42)}=18.87, p<0.01\right]$. However, there was no significant main effect of sex and no significant interaction of group $\times$ sex or time $x$ sex. The righting reflex score significantly increased overtime. The FLX group have a significantly delayed righting reflex compared with the NS group. The dataset was split by sex for further analysis.

In males, there was a significant main effect of group $\left[F_{(1,17)}=5.41, p=0.033\right]$, post-hoc analysis confirmed that delayed righting reflex in the FLX group occurred during PND 4-7 ( $p<0.05)$ (Fig. 2C).

In females, there was a significant main effect of time $\left[F_{(4,22)}=3.76, p=0.007\right]$ and group $\left[F_{(1,25)}=16.13\right.$, $p<0.01$ ] and post-hoc analysis (Bonferroni test) revealed a significantly delayed righting reflex in the FLX group occurred during PND 3-7 ( $<<0.05$ ) except PND 5 ( Fig. 2D).

2.2 Cliff Avoidance

There was a significant main effect of time $\left[F_{(3,50)}=13.98, p<0.01\right]$, meaning cliff avoidance became more visible over time, as would be expected. However, there was no main effect of group or sex and no significant interaction of group $\times$ sex or time $\times$ sex.

\section{Behavioral Tests}

Suspension test

The suspension test was used to assess neuromotor function. Firstly,data were combined across sex for analysis. There was a significant main effect of time $\left[F_{(4,50)}=106.77, p<0.01\right]$ and group $\left[F_{(1,50)}=12.85\right.$, 
$p=0.001]$. However, there was no significant main effect of sex and no significant interaction of group $x$ sex or time $\times$ sex. The suspension time significantly increased over the course of tests. The FLX group showed significantly delayed neuromotor function compared with the NS group. The dataset was split by sex for further analysis.

In males, repeated-measures ANOVA showed no significant difference of suspension time between the $F L X$ and control group. However, there was a significant main effect of time $\left[F_{(4,25)}=53.52, p<0.01\right]$. Post hoc analysis confirmed that suspension time was significantly reduced in the FLX group compared to control group at PND 14 ( $p=0.022)$ (Fig. 2E).

In females, there was a significant main effect of time $\left[F_{(4,22)}=55.06, p<0.01\right]$, group $\left[F_{(1,25)}=21.93, p<\right.$ $0.01]$ and an interaction between group and time $\left[F_{(4,22)}=6.91, p<0.01\right]$ and post hoc analysis revealed suspension time was significantly reduced in the FLX group at PND $14(p=0.022), 18(p=0.002)$, and $20(p=0.005)$ compared to control group(Fig. 2F).

Buried Food Pellet Test

A 2 (groups (FLX or NS)) $\times 2$ (sex (male or female)) general linear model (GLM) was performed to investigate whether the FLX and control groups differed in the latency to find buried food pellets. There was a significant main effect of group $[F(1,50)=9.06, p=0.004]$ and an interaction between group and $\operatorname{sex}[F(1,50)=5.11, p=0.028]$. Thus the dataset was split by sex for further analysis. In female rats there was no significant difference between FLX and NS groups in the latency to find buried food pellets. Whilst male, rats prenatally exposed to FLX show significantly longer latency to find buried food pellets than the male NS group $[F(1,50)=13.89, p<0.01]$ (Fig. $2 G$ ).

\section{Open Field Test}

Data from the OFT were analyzed by a 2 (groups (FLX, or NS)) $\times 2$ (sex (male or female)) general linear model (GLM). The total distance travelled in $5 \mathrm{~min}$ in the open field was taken as a measure of motor function and anxiety-related behaviors were measured by duration in the central area. The duration in the central area show no significant main effects of group or sex, however, there was an interaction between group $\times \operatorname{sex}\left[F_{(1,48)}=7.58, p=0.008\right]$. Thus the dataset was split by sex for further analysis. Male rats who were prenatally exposed to FLX spent significantly less time in the center area compared to the male NS group $\left[F_{(1,48)}=4.86, p=0.032\right]$ ( $F i g .2 G$ ), whilst the females showed no difference between groups (Fig. 2H). There was no significant main effect of sex or group on total distance moved in the area, without significant interaction between group and sex (Fig. 2l).

Social Ability

Social interaction was evaluated by comparing distance walked in the strange rat chamber with distance walked in the empty chamber. In addition, locomotor activity and sociability were assessed by the number of entries from center chamber to another chamber (the chamber with stranger rat or empty chamber). 
There was a significant main effect of distance $\left[F_{(2,38)}=42.44, p<0.01\right]$ and group $\left[F_{(1,38)}=12.37, p=\right.$ 0.001]. However, there was no significant main effect of sex and no significant interaction of group $\times$ sex or distance $\times$ sex. The dataset was still split by sex for further analysis to keep a consistent of analysis with other tests.

In males, there was a significant main effect of distance $\left[F_{(2,20)}=15.07, p<0.01\right]$ and group $\left[F_{(1,20)}=7.79\right.$, $p=0.011]$. The results of the sociability test showed that the male NS group moved significantly more distance in the strange rat chamber than in the empty chamber (strange rat chamber vs empty chamber, $p=0.004)$. However, in the male FLX group there was no significant difference in the distance moved in the chamber containing a stranger compared to the empty chamber (strange rat chamber vs empty chamber, $p=0.287$ ). Furthermore, FLX-exposed rats moved less distance in the chamber containing a strange rat than NS-exposed rats, but the difference was not significant (FLX-exposed rats in the strange rat chamber vs NS-exposed rats in the strange rat chamber, $p=0.069$ ), initiating fewer social interactions than controls (Fig. $2 \mathrm{~J}$ ). In addition, in males, there was a significant main effect of number of entries into each side chamber $\left[F_{(1,20)}=20.78, p<0.01\right]$. However, there was no main effect of group or significant group $\times$ entries interaction. Post hoc testing confirmed that the prenatal FLX exposed group showed no significant difference in the number of entries into the strange rat or empty side chambers. Whereas, the NS group had a higher number of entries into the strange rat side chamber than the empty side $(p<0.01)$, indicating a social deficit and decreased locomotor activity in FLX group. (Fig. 2K).

In females, there was a significant main effect of distance $\left[F_{(2,18)}=44.51, p<0.01\right]$ and group $\left[F_{(1,18)}=\right.$ $4.87, p=0.04]$. The female NS exposed group moved significantly more distance in the chamber containing a strange rat than in the empty chamber (strange rat chamber vs empty chamber, $p=0.001$ ). FLX-exposed female rats also moved significantly more distance in the chamber containing a strange rat than in the empty chamber (strange rat chamber vs empty chamber, $p<0.001$ ). There was no difference between the prenatal FLX and NS-exposed female rats in terms of the distance moved in the chamber containing a stranger (Fig. 2L). There was a significant main effect of number of entries into each side chamber in females $\left[F_{(1,18)}=44.28, p<0.01\right]$. However, there was no main effect of group or significant group $\times$ entries interaction. Post hoc testing confirmed that both FLX and NS groups showed an increased number of entries into strange rat side chamber compared to the empty side $(p<0.001)$. At the same time, there was no significant difference in the number of entries into the strange rat chamber or the empty side chamber between the two groups (Fig. 2M). These results indicate that FLX and NS-exposed rats had no significant difference in locomotor activity and sociability in females, whereas, the male offspring prenatally exposed to FLX showed impaired sociability and decreased locomotor activity.

\section{Western Blot And Immunofluorescence Of SERT and TPH}

SERT and TPH expression in the prefrontal cortex and raphe nuclei were measured at PND 7 and PND 35 using western blot and immunofluorescence.

SERT expression 
There were no significant main effect of sex or group on SERT expression in the prefrontal cortex at PND 7 , without significant interaction of group $\times$ sex. Both male and female rats showed no significant effect on SERT expression in the prefrontal cortex at PND 7. There was a significant main effect of sex $[F(1,23)$ $=4.63, p=0.042]$ in the raphe nuclei at PND 7. But there was no significant main effect of group nor any sex $\times$ group interaction. The dataset was therefore split by sex for further analysis, also (Fig. 3A, B). There were no significant main effects of group on SERT level in the prefrontal cortex at PND 35. Post-hoc comparisons revealed that SERT expression decreased in prenatal FLX exposed male offspring in the prefrontal cortex at PND $35(p=0.039)$. There were no significant main effect of sex or group on SERT expression in the raphe nuclei at PND 35, without significant interaction of group $\times$ sex. Both male and female rats showed no significant effect on SERT expression in the raphe nuclei at PND 35 (Fig. 3C, D). $\mathrm{SERT}^{+}$cells were observed in the neurons of the prefrontal cortex in all the groups using immunofluorescence (Supplementary Fig. 2).

\section{TPH expression}

There was a significant main effect of $\operatorname{sex}\left[F_{(1,23)}=9.34, p=0.006\right]$ in the prefrontal cortex at PND 7. But there was no significant effect of group or significant group $\times$ sex interaction. The dataset was split by sex for further analysis. Only male rats prenatally exposed to fluoxetine had significantly increased expression of TPH in the prefrontal cortex at PND $7(p=0.037)$. There were no significant main effects of sex or group on TPH expression in the raphe nuclei at PND 7. No sex $\times$ group interaction was observed on TPH expression. Both male and female rats showed no significant effect on TPH expression in the raphe nucleus at PND 7 (Fig. 3E, F). However, there was a significant main effect of group $\left[F_{(1,15)}=6.50, p=\right.$ 0.022] on TPH expression in the prefrontal cortex at PND 35. Although there was no significant effect of sex or significant group $\times$ sex interaction. The dataset was split by sex for further analysis. Only male rats prenatally exposed to FLX had a significantly increased expression of TPH in the prefrontal cortex at PND $35(p=0.014)$. Both male and female rats showed no significant effect on TPH expression in the raphe nuclei at PND 35 (Fig. 3G, H). TPH cells were observed in neurons of the prefrontal cortex in all the groups by immunofluorescence (Supplementary Fig. 3).

\section{5-HT Level}

5-HT levels in the prefrontal cortex and raphe nuclei were measured at PND 35 with sandwich enzymelinked-immunosorbent assay. There was a significant main effect of group $[F(1,8)=8.94, p=0.017]$ on 5$H T$ levels in the prefrontal cortex at PND 35. But there was no significant main effect of sex nor any sex $x$ group interaction. The groups were split by sex for further analysis. Post-hoc comparisons revealed that the male rats in FLX group had a lower 5-HT level in the prefrontal cortex compared to male NS control rats at PND $35\left[F_{(1,8)}=9.89, p=0.014\right]$, whilst there was no difference in the females (Fig. 4A, B). There was no significant difference in 5-HT levels in the raphe nuclei of both sexes at PND 35 (Fig. 4A, B). These results indicate that prenatal FLX exposure resulted in decreased 5-HT levels in the prefrontal cortex of male rats at PND 35. 


\section{Brain Metabolites Measured by H-MRS}

Brain metabolites of $\mathrm{NAA} / \mathrm{tCr}$ and $\mathrm{tCho} / \mathrm{tCr}$ were measured in the medial prefrontal cortex of $\mathrm{FLX}$ and $\mathrm{NS}$ groups at PND 35.

In the medial prefrontal cortex, there was a significant main effect of group on $\mathrm{NAA} / \mathrm{tCr}\left[\mathrm{F}_{(1,12)}=11.54, \mathrm{p}\right.$ $=0.005]$, but no significant main effect of sex or any group $\times$ sex interaction. Post-hoc testing confirmed that there was a significant lower metabolism of NAA/tCr in the FLX group compared with the control group in male rats $(p=0.008)$, while the females showed no difference. There was no significant main effect of sex or group on brain metabolites of tCho/tCr in FLX and NS-exposed rats in the medial prefrontal cortex, without significant group $\times$ sex interaction (Fig. 5).

\section{Proteomics}

2DE and MALDI-TOF-MS/MS were conducted to examine whether prefrontal cortex protein expression was altered by prenatal fluoxetine exposure. Wide-range $\mathrm{pH}$ 3-10 strips were used to investigate whether there was differential expression of proteins in the FLX group, compared with the NS group.

In males, protein spots were visualized by silver staining across 6 gels (saline: $n=3$ males, FLX: $n=3$ males). The partial least squares discriminant analysis (PLS-DA) included all spots, which clearly separated protein expression in rats exposed to FLX from NS controls (Fig. 5F). A 1.5-fold change was used as a threshold to identify the differential proteins in the 2-DE gels. Analysis of covariance revealed significant differences in protein expression in 24 spots. Six of these spots with the smallest differences within groups and the most remarkable differences between groups were selected for mass spectrometry. Specific proteins which were found to be differentially expressed included tubulin beta-3 chain (TUBB3), 14-3-3 protein gamma (14-3-3-ү), aconitate hydratase mitochondrial (mAH), fructose-bisphosphate aldolase A (FBA), dihydropyrimidinase-like 4 (DPYSL4), and voltage-dependent anion-selective channel protein 2 (VDAC2), which were classified into signal transducers, energy metabolism, neurogenesis, anion transport and apoptosis (Table 2). TUBB3, is a beta-tubulin isotypes which exists in microtubules, it has an important role in axon guidance and maturation ${ }^{[55]}$. 14-3-3-үis a cytoplasmic protein, which is involved in signal transduction ${ }^{[56]}$. DPYSL4 is a protein which is highly expressed in the nervous system, and has the ability to inhibit axonal growth in the process of neurogenesis ${ }^{[57]}$. VDAC2 participates in anion transport and the apoptotic signaling pathway ${ }^{[58]}$. mAH plays an important role in the tricarboxylic acid cycle and is involved in energy metabolism ${ }^{[59]}$. FBA is a type of glycolytic enzyme, associated with the biosynthetic processing of ATP and cell shape ${ }^{[60]}$. 
Table 2

Differential Proteins in the prefrontal cortex of male rats in both FLX and NS groups

\begin{tabular}{|lllllll|}
\hline $\begin{array}{l}\text { Spot } \\
\text { No. }\end{array}$ & $\begin{array}{l}\text { Fold } \\
\text { difference } \\
(\mathrm{F} / \mathrm{N})\end{array}$ & P value & Protein name & NCBI no. & $\begin{array}{l}\text { Biological } \\
\text { process }\end{array}$ \\
\hline 9 & $0.390187 \downarrow$ & 0.000607 & Tubulin beta-3 chain & Gil 246118 & $\begin{array}{l}\text { axon guidance } \\
\text { and maturation }\end{array}$ \\
\hline 117 & $0.461474 \downarrow$ & 0.003486 & $\begin{array}{l}14-3-3 \text { protein gamma } \\
\text { ail } 56010\end{array}$ & $\begin{array}{l}\text { signal } \\
\text { transduction }\end{array}$ \\
\hline 7207 & $2.08296 \uparrow$ & 0.00668 & $\begin{array}{l}\text { Voltage-dependent anion- } \\
\text { selective channel protein 2 }\end{array}$ & $\begin{array}{l}\text { Gil } \\
100911742\end{array}$ & $\begin{array}{l}\text { neurogenesis } \\
\text { anion } \\
\text { transport, } \\
\text { apoptotic }\end{array}$ \\
\hline 7807 & $0.49573 \downarrow$ & 0.00056 & Aconitate hydratase & $\begin{array}{l}\text { Gil } \\
102553494\end{array}$ & $\begin{array}{l}\text { energy } \\
\text { metabolic } \\
\text { process }\end{array}$ \\
\hline 8415 & $2.180734 \uparrow$ & 0.000295 & $\begin{array}{l}\text { Fructose-bisphosphate aldolase } \\
\text { A }\end{array}$ & Gil 24189 & $\begin{array}{l}\text { energy } \\
\text { metabolic } \\
\text { process }\end{array}$ \\
\hline
\end{tabular}

In females, protein spots were visualized by silver staining across 6 gels (saline: $n=3$ females; FLX: $n=3$ females). The partial least squares discriminant analysis (PLS-DA) included all spots, which clearly separated protein expression in rats exposed to FLX from NS control (Fig. 5G). To identify protein expression differences in the 2-DE gels, a 1.5-fold change was used as a threshold. Analysis of covariance revealed significant expression differences in 15 spots. Seven spots were selected with the smallest differences within groups and the most remarkable differences between groups for mass spectrometry. Specific proteins which were found to be differentially expressed included disulfideisomerase A3 (PDIA3), annexins (ANX), s-formylglutathione hydrolase (SFGH). proteasome subunit beta type-7 (PSMB7), and peroxiredoxin 3 (PRDX3), which were classified into redox homeostasis, catabolic processing and cell migration (Table 3). PDIA3 an oxidoreductase, with a specific effect on glycoproteins due to links with calreticulin and calnexin ${ }^{[61]}$. Annexins act as $\mathrm{Ca}^{2+}$ binding proteins in a variety of species. Previous studies showed that Annexin A3 (ANXA3) is related to cell migration and plexus formation in endothelial cells ${ }^{[62]}$. SFGH, a kind of anti-oxidant, the function is to catalyze the conversion of S-formylglutathione to glutathione. Also, close to cellular oxidative stress ${ }^{[63]}$. PSMB7 is an ATPdependent protease complex and is essential for protein catabolic process ${ }^{[64]}$. PRDX3, an antioxidant enzyme can reduce hydrogen peroxide into water, eliminating approximately $90 \%$ mitochondrial hydrogen peroxide. It is essential for the cell redox homeostasis ${ }^{[65]}$. 
Table 3

Differential proteins in the prefrontal cortex of female rats in both FLX and NS groups

\begin{tabular}{|clllll|}
\hline $\begin{array}{l}\text { Spot } \\
\text { No. }\end{array}$ & $\begin{array}{l}\text { Fold } \\
\text { difference } \\
\text { (N/F) }\end{array}$ & $\begin{array}{l}\text { P } \\
\text { value }\end{array}$ & Protein name & NCBI no. & Biological process \\
\hline 80 & $1000000 \uparrow$ & 0.04 & $\begin{array}{l}\text { Protein disulfide } \\
\text { isomerase A3 }\end{array}$ & Gi| 29468 & redox homeostasis \\
\hline 360 & $1.79013 \uparrow$ & 0.04 & Annexin A3(ANXA3) & Gi| 25291 & $\begin{array}{l}\text { cell migration and plexus } \\
\text { formation }\end{array}$ \\
\hline 361 & $1.61714 \uparrow$ & 0.04 & $\begin{array}{l}\text { S-formylglutathione } \\
\text { hydrolase }\end{array}$ & $\begin{array}{l}\text { Gi| } \\
102549599\end{array}$ & $\begin{array}{l}\text { catabolic process, } \\
\text { oxidative stress }\end{array}$ \\
\hline 421 & $1.60494 \uparrow$ & 0.01 & $\begin{array}{l}\text { Proteasome subunit } \\
\text { beta type-7 }\end{array}$ & Gil 85492 & protein catabolic process \\
\hline 464 & $1.60614 \uparrow$ & 0.04 & $\begin{array}{l}\text { Peroxiredoxin 3 } \\
\text { pela }\end{array}$ & Gil 64371 & cell redox homeostasis \\
\hline
\end{tabular}

Western blot analysis of the prefrontal cortex from animals without behavioral testing confirmed that DPYSL4 expression was significantly elevated in male rats exposed to FLX (Fig. 5H). Moreover, males prenatally exposed to FLX showed significantly lower expression of 14-3-3 protein gamma (Fig. $5 \mathrm{I}$ ) in the prefrontal cortex, as compared with NS males. In females PRDX3 was significantly lowered in the prefrontal cortex of rats prenatally exposed to FLX versus NS (Fig. $5 \mathrm{~J}$ ).

\section{Discussion}

We believe this study provides the first evidence that postnatal behavioral differences in the offspring of dams exposed to prenatal SSRI are accompanied by differences and dysfunction of the 5-HT system in the prefrontal cortex; and that both the behavioral and neurochemical sequelae are sex-dependent. We found that fluoxetine exposure, via the mother, showed delayed physical development, increased anxiety and impaired social interaction in offspring, particularly in male offspring, this mimics the phenotype of autism in humans. Moreover, prenatal fluoxetine exposure significantly affected development of the serotonergic neurotransmission system (down-regulation of 5-HT and SERT expression and up-regulation of TPH levels) in the prefrontal cortex of male offspring. We also found that prenatal FLX exposure significantly decreased NAA/tCr with ${ }^{1} \mathrm{H}-\mathrm{MRS}$ in the prefrontal cortex. Thus these data contribute to our understanding that prenatal FLX exposure simulates the phenotype of autism in rat offspring, probably resulting from dysfunction of the serotonin system. In addition, we show for the first time that prenatal exposure to SSRIs in rats leads to long-term alterations in protein expression in the prefrontal cortex, which is also sex-dependent. More specifically, proteins involved in signal transduction, energy metabolism and neurogenesis were found to have altered expression levels in prenatal FLX exposed male offspring, including 14-3-3-y-protein, mAH, FBA, DPYSL4, and VDAC2; while prenatal FLX exposed female 
offspring had proteomic changes in proteins involved inredox homestasis, apotosis and inflammation in the prefrontal cortex, including elevated levels of PDIA3, PRDX3, and ANXA3.

Abnormal neurophysical development in offspring

The physical development of the FLX exposed rat offspring was assessed based on a battery of tests recommended by Bairy and Madhyastha ${ }^{[66]}$. In the present work, the offspring exposed to FLX had a lower body weight, delayed righting reflex, abnormal motor function and olfactory function compared to NS control rats. The weight gained during preweaning was reduced in rat offspring exposed to FLX during fetal life. This is consistent with the findings from previous studies ${ }^{[38,66]}$. In addition, FLX exposed offspring showed significantly delayed righting reflex in both sexes, compared to NS exposed control offspring. This delay corresponds well with findings from Deiro and colleagues, who found a delay in reflex development in rats postnatally exposed to citalopram ${ }^{[67]}$. In the suspension test, FLX exposed offspring fell earlier than the NS exposed control group offspring in early-life, this was especially apparent in females. In the buried food pellet paradigm, only male offspring prenatally exposed to FLX showed a longer time to search for the food pellet in our study. This increased time spent searching for the buried food pellet could indicate reduced olfactory function. This is consistent with a study by Kroeze et al. reporting that the development of olfactory function is delayed in male rats who are exposed to FLX during the perinatal period ${ }^{[38]}$.

Increased anxiety-like behavior

The total distance in the open field may be used as an indicator of locomotor activity ${ }^{[68]}$, whilst the time spent in the central area may be used as an indicator of anxiety-like behavior, in rats ${ }^{[69]}$. In this study, an increase in anxiety-like behavior in the open field test was found in male offspring prenatally exposed to FLX. This is broadly consistent with previous reports that perinatal exposure to FLX causes increased anxiety in the open field in offspring ${ }^{[70-72]}$. However, these studies did not separate by sex. Moreover, some studies have shown that perinatal FLX exposure does not alter anxiety in adolescent or adult animals $^{[73-75]}$. The different timing and dose of FLX exposure may account for these discrepancies.

Impaired social interaction

In the present study, impaired social interaction was observed in male offspring prenatally exposed to FLX, this is congruent with a previous report ${ }^{[76]}$. In addition, lower sexual activity has been reported in male offspring perinatally exposed to SSR ${ }^{[9,77]}$. There is a wealth of literature that describes the relationship between 5-HT and social interaction. For example, SSRIs and 5-HT releasing drugs are known to reduce social behavior as well as sexual behavior in humans ${ }^{[78-82]}$.

Dysfunction of 5-HT system

The 5-HT system plays a key role in neurodevelopment which may contribute to the neurophysical and behavioral alterations mentioned above. In this study, prenatal FLX exposure caused down-regulation of 
5-HT levels in the prefrontal cortex of male offspring. It is known that intracellular and extracellular 5-HT levels are controlled by the expression of SERT and TPH ${ }^{[83]}$. Concordantly, we found that SERT levels in the prefrontal cortex were significantly reduced at PND 35 in male offspring exposed to FLX prenatally. Thus FLX exposure during fetal development changes the serotonin homeostasis. Changes in serotonergic function and signaling have been reported to be associated with $\mathrm{ASD}^{[84]}$. For example, SPECT analysis has shown reduced SERT binding capacity in the medial frontal cortex of autistic children, ${ }^{[85]}$. In addition, SERT is encoded by SLC6A4, and found associations of the SLC6A4 polymorphism with ASD

[86, 87]. Furthermore mutant SERT knockout mice have been reported to display increased anxiety- and depression-like behaviors, decreased social behavior, and exaggerated response to environmental stress, imitating the phenotype of autism ${ }^{[88]}$.

TPH is the rate-limiting enzyme in the synthesis of 5-HT. In our study, we observed a significant increase in prefrontal TPH expression in male offspring at PND 7 and PND 35 exposed to FLX compared to the NS exposed control group. We suspect this may be due to the negative feedback of down-regulated 5-HT in the brain. Klomp et al ${ }^{[89]}$ has previously reported that there is increased TPH immunoreactivity in the dorsal raphe nuclei of FLX treated rats in adolescence, but the TPH levels are then reduced once they become adult rats. In addition, Baik and colleague ${ }^{[90]}$ have reported in vitro measurement of TPH mRNA is increased after the FLX treatment. On the other hand, some studies have shown that neonatal exposure to another SSRI, citalopram, results in a significant reduction in TPH expression in the male raphe nuclei and this persists into adulthood ${ }^{[77,91]}$. The different timing and drug of exposure may account for these differences between our study and others in the effects on TPH expression.

Decreased levels of NAA/tCr in the medial prefrontal cortex

In our study, we observed a decreased level of NAA/tCr in the medial prefrontal cortex in male offspring prenatally exposed to FLX. NAA is synthesized in the mitochondria and located predominantly in neural bodies, dendrites, and axons ${ }^{[92]}$. As a marker of neuronal activity, a regional decrease of NAA may be an indication of neuronal malfunction ${ }^{[93]}$. Emiko and colleagues ${ }^{[94]}$ have reported a reduction of NAA/tCr in the anterior cingulate cortex and left dorsolateral prefrontal cortexof autistic individuals. Through the use of MRS their team ${ }^{[95]}$ have also demonstrated reduced NAA in the left amygdala and the bilateral orbitofrontal cortex in autistic children. In addition Horder and colleagues ${ }^{[96]}$ have reported that NAA concentration both in the basal ganglia and the dorsolateral prefrontal cortex is significantly decreased in autistic adults compared to a neurotypical control group. This finding was positively correlated with impaired social communication. It is possible that the neuronal dysfunction in the medial prefrontal cortex shown in this study may have contributed to the deficits in sociability or anxiety-like behavior. Importantly, we have provided the first in vivo evidence to demonstrate the sex differences of NAA/tCr levels in rat offspring prenatally exposed to FLX compared to controls. This has translational implications for research in children with autism or other neurodevelopmental disorders. 
The differentially expressed proteins screening by proteomics

In the present study, we demonstrated a wide spectrum of proteomic changes in the prefrontal cortices of adolescent male and female rats with prenatal exposure to FLX. Based on the uniprot database and previous studies $^{[97-100]}$, we have found that the FLX exposed males showed differential expression of proteins involved in signal transduction, energy metabolism and neurogenesis, whereas the FLX exposed females showed differential expression of proteins involved in redox homeostasis.

Signal transducer

Male offspring with prenatal FLX exposure had down-regulation of 14-3-3 protein gamma in the PFC; this was confirmed by western blot analysis. The family of 14-3-3 proteins consists of seven distinct isoforms $(\beta, \gamma, \varepsilon, \zeta, \eta, \sigma a n d \tau)$, which bind a multitude of signaling molecules to control signal transduction ${ }^{[101]}$. Studies have shown that deletions of the 14-3-3 protein family are associated with a variety of neuropsychological disorders, including autism ${ }^{[102]}$, schizophrenia ${ }^{[103]}$ and bipolar disorder ${ }^{[104,105]}$. Studies have found that deficits of 14-3-3 proteins could be associated with autism spectrum disorder, due to disruption of melatonin synthesis ${ }^{[106,107]}$. Moreover, Cheah and colleagues ${ }^{[108]}$ confirmed that reduced levels of 14-3-3 3 causes neurodevelopmental anomalies in mice similar to neuropsychiatric disorders such as autism spectrum disorder, schizophrenia and bipolar disorder. Other researchers have reported that 14-3-3Z deficient mice show behavioral and anatomical defects related to neurodevelopmental disorders by affecting hippocampal and ventricular function ${ }^{[109]}$. Diminished 14-3-3 proteins have also been demonstrated in the prefrontal cortex in a maternal separation model ${ }^{[110]}$. These findings are congruous with our data presented here. The relationship between decreased 14-3-3 proteins and autism in male offspring requires further investigation.

\section{Energy metabolism}

Our study found a significant decrease in the level of the energy metabolism-associated protein; $\mathrm{mAH}$, in male offspring prenatally exposed to FLX. This is consistent with findings in autistic children ${ }^{[99]}$. In addition, FBA, another energy metabolism-associated protein, was significantly increased. A similar finding has been reported by Głombik et al, who found up-regulation of FBA in the hippocampus in male offspring prenatally exposed to chronic FLX administration ${ }^{[111]}$.

Neurogenesis

The results of the present study demonstrate that, DPYSL4, a neurogenesis-associated protein, is significantly increased in the PFC in male offspring prenatally exposed to FLX. DPYSL4 is also known as collapsin response mediator protein 3 (CRMP3), and belongs to the cytosolic phosphoprotein family, consisting of five homologous cytosolic proteins, CRMP1-5 ${ }^{[112]}$. Studies have shown that CRMP3 participates in axonal outgrowth ${ }^{[113]}$, axonal guidance ${ }^{[114]}$ and neuronal plasticity ${ }^{[115]}$, similar to CRMP4 ${ }^{[16]}$. Additionally, a previous study has reported elevated expression levels of CRMP4 in a mouse 
model of depression ${ }^{[97]}$. It has further been reported that Crmp4-KO mice show ASD characteristics, such as decreased social interaction and altered sensory responses and most of these changes were more severe in male Crmp4-KO mice than in females ${ }^{[17]}$.

Redox homeostasis

Biomarkers of oxidative stress have been reported in many neuropsychiatric disorders, including autism $^{[118-121]}$, Parkinson's disease ${ }^{[122]}$, Alzheimer's disease ${ }^{[123]}$, schizophrenia ${ }^{[124]}$ and bipolar disorder ${ }^{[125]}$. In our study, we found significantly decreased levels of the redox homeostasis-associated proteins PDIA3 and PRDX3 in the PFC in female offspring prenatally exposed to FLX. Rose et. al. have reported decreased redox/antioxidant capacity and increased oxidative stress in the post-mortem autism brain ${ }^{[99]}$. This is also in agreement with the hypothesis of oxidative stress in the induction of autism reported by Parker et al ${ }^{[118]}$.

Limitations

We first acknowledge that only one social ability test might not be enough to investigate the complex picture of social function. Since impaired social function is one of the core behavioral phenotypes of autism, more complex social tests should be applied on this model in the future. Second, we observed the expression levels of SERT and TPH only on neuron. It would be more precise if the expression levels of SERT and TPH in serotoninergic neurons are detected and quantified in the future experiments.

\section{Conclusion}

To the best of our knowledge, these experiments provide the first direct experimental evidence that sexdependent ex vivo dysfunction of the serotonergic system, and in vivo metabolic changes, and behavioral effects of prenatal FLX exposure are linked. A proteomic study also showed sex-dependent, prenatal FLX dependent differential protein expression in the PFC. Further studies will target these proteins as promising candidates for controlling the effects of prenatal FLX admission.

\section{Declarations}

\section{Funding}

The research was supported by the Natural Science Foundation of China (NSFC, NO. 81260296), and the Research Fund for the Doctoral Program of Kunming Medical University

\section{Availability of data and materials}

Not applicable.

\section{Authors' contributions}


Conceived and designed the experiments: LJA, PCS and QL. Performed the experiments: MXC, SC and LL, AJL. Analyzed the data: MXC, QLiu, CUW, SC, LL, XFZ, QL. Contributed reagents/materials/analysis tools: QL, PCS, LJA. Wrote and revised the paper: MXC, SC, LL, CUW, MJL, PCS, QL, LJA. All authors have approved the final manuscript version.

\section{Ethics approval and consent to participate}

Not applicable.

\section{Consent for publication}

Not applicable.

\section{Competing interests}

The authors declare that they have no competing interests.

\section{Publisher's Note}

Springer Nature remains neutral with regard to jurisdictional claims in published maps and institutional affiliations.

\section{Author details}

${ }^{1}$ School of Rehabilitation, Kunming Medical University, Kunming, China. ${ }^{2}$ Department of Rehabilitation, China Resources \& WISCO General Hospital, Wuhan, China. ${ }^{3}$ Rehabilitation Medicine Department, The Affiliated Hospital of Southwest Medical University, Tai Ping Road, Luzhou, Sichuan, China. ${ }^{4}$ Medical Sciences Division, University of Oxford, UK. ${ }^{5}$ Department of Surgery, The Chinese University of Hong Kong, Hong Kong SAR, China. ${ }^{6}$ Department of Psychiatry, Tongji Hospital of Huazhong University of Science and Technology (HUST). ${ }^{7}$ University of Notre Dame, 104 Keough Hall Notre Dame, IN 46556, USA. ${ }^{8}$ Department of Psychiatry, ${ }^{9}$ State Key Laboratory of Brain and Cognitive Sciences, ${ }^{10}$ Centre for Genomic Sciences, The University of Hong Kong, Hong Kong SAR, China.

*Equal contribution

\#Correspondence to:

Prof. Li Juan Ao, School of Rehabilitation, Kunming Medical University, Kunming, China. Telephone: +86 13508710081; lijuanao@hotmail.com; and Dr. Qi Li, Department of Psychiatry, The University of Hong Kong, Hong Kong SAR, China. Telephone: +852 98236989; liqi@hku.hk.

\section{References}


1. Kessler R C, Berglund P, Demler O, et al. Lifetime prevalence and age-of-onset distributions of DSM-IV disorders in the National Comorbidity Survey Replication[J]. Arch Gen Psychiatry, 2005, 62(6): 593-602. 2. Austin M P, Kildea S, Sullivan E. Maternal mortality and psychiatric morbidity in the perinatal period: challenges and opportunities for prevention in the Australian setting[J]. Med J Aust, 2007, 186(7): 364367.

3. Woody C A, Ferrari A J, Siskind D J, et al. A systematic review and meta-regression of the prevalence and incidence of perinatal depression[J]. J Affect Disord, 2017, 219: 86-92.

4. El $\mathrm{M} \mathrm{H}$, Jaddoe $\mathrm{V} W$, Hudziak J J, et al. Maternal use of selective serotonin reuptake inhibitors, fetal growth, and risk of adverse birth outcomes[J]. Arch Gen Psychiatry, 2012, 69(7): 706-714.

5. Huang $\mathrm{H}$, Coleman S, Bridge $\mathrm{J} \mathrm{A}$, et al. A meta-analysis of the relationship between antidepressant use in pregnancy and the risk of preterm birth and low birth weight[J]. Gen Hosp Psychiatry, 2014, 36(1): 1318.

6. Myles $\mathrm{N}$, Newall $\mathrm{H}$, Ward $\mathrm{H}$, et al. Systematic meta-analysis of individual selective serotonin reuptake inhibitor medications and congenital malformations[J]. Aust N Z J Psychiatry, 2013, 47(11): 1002-1012. 7. Gemmel M, Bogi E, Ragan C, et al. Perinatal selective serotonin reuptake inhibitor medication (SSRI) effects on social behaviors, neurodevelopment and the epigenome[J]. Neurosci Biobehav Rev, 2018, 85: 102-116.

8. Popa D, Lena C, Alexandre C, et al. Lasting syndrome of depression produced by reduction in serotonin uptake during postnatal development: evidence from sleep, stress, and behavior[J]. J Neurosci, 2008, 28(14): 3546-3554.

9. Gouvea T S, Morimoto H K, de Faria M J, et al. Maternal exposure to the antidepressant fluoxetine impairs sexual motivation in adult male mice[J]. Pharmacol Biochem Behav, 2008, 90(3): 416-419.

10. Favaro P, Costa L C, Moreira E G. Maternal fluoxetine treatment decreases behavioral response to dopaminergic drugs in female pups[J]. Neurotoxicol Teratol, 2008, 30(6): 487-494.

11. Croen L A, Grether J K, Yoshida C K, et al. Antidepressant use during pregnancy and childhood autism spectrum disorders[J]. Arch Gen Psychiatry, 2011, 68(11): 1104-1112.

12. Eriksson M A, Westerlund J, Anderlid B M, et al. First-degree relatives of young children with autism spectrum disorders: some gender aspects[J]. Res Dev Disabil, 2012, 33(5): 1642-1648.

13. Gidaya N B, Lee B K, Burstyn I, et al. In utero exposure to selective serotonin reuptake inhibitors and risk for autism spectrum disorder[J]. J Autism Dev Disord, 2014, 44(10): 2558-2567.

14. Harrington R A, Lee L C, Crum R M, et al. Prenatal SSRI use and offspring with autism spectrum disorder or developmental delay[J]. Pediatrics, 2014, 133(5): e1241-e1248.

15. Hviid A, Melbye M, Pasternak B. Use of selective serotonin reuptake inhibitors during pregnancy and risk of autism[J]. N Engl J Med, 2013, 369(25): 2406-2415.

16. Rai D, Lee B K, Dalman C, et al. Parental depression, maternal antidepressant use during pregnancy, and risk of autism spectrum disorders: population based case-control study[J]. BMJ, 2013, 346: f2059. 17. Sorensen M J, Gronborg T K, Christensen J, et al. Antidepressant exposure in pregnancy and risk of autism spectrum disorders[J]. Clin Epidemiol, 2013, 5: 449-459.

18. Ornoy A. Neurobehavioral risks of SSRIs in pregnancy: Comparing human and animal data[J]. Reprod Toxicol, 2017, 72: 191-200. 
19. Viktorin A, Uher R, Reichenberg A, et al. Autism risk following antidepressant medication during pregnancy[J]. Psychol Med, 2017, 47(16): 2787-2796.

20. Kim J Y, Son M J, Son C Y, et al. Environmental risk factors and biomarkers for autism spectrum disorder: an umbrella review of the evidence[J]. Lancet Psychiatry, 2019, 6(7): 590-600.

21. Zhong P, Yuen E Y, Yan Z. Modulation of neuronal excitability by serotonin-NMDA interactions in prefrontal cortex[J]. Mol Cell Neurosci, 2008, 38(2): 290-299.

22. Bright $F$ M, Byard $R$ W, Vink $R$, et al. Normative distribution of substance $P$ and its tachykinin neurokinin-1 receptor in the medullary serotonergic network of the human infant during postnatal development[J]. Brain Res Bull, 2018, 137: 319-328.

23. Forero A, Rivero O, Waldchen S, et al. Cadherin-13 Deficiency Increases Dorsal Raphe 5-HT Neuron Density and Prefrontal Cortex Innervation in the Mouse Brain[J]. Front Cell Neurosci, 2017, 11: 307. 24.Brown H K. Prenatal Selective Serotonin Reuptake Inhibitor Exposure and Child Neurodevelopment: The Importance of Maternal Mental IIIness[J]. J Am Acad Child Adolesc Psychiatry, 2018, 57(3): 151-152. 25.Andalib S, Emamhadi M R, Yousefzadeh-Chabok S, et al. Maternal SSRI exposure increases the risk of autistic offspring: A meta-analysis and systematic review[J]. Eur Psychiatry, 2017, 45: 161-166.

26.Vigod S N, Gomes T, Ray J G. Prenatal Antidepressant Use and Autism Spectrum Disorder-Reply[J]. JAMA, 2017, 318(7): 665.

27. Ackerman S, Schoenbrun S, Hudac C, et al. Interactive Effects of Prenatal Antidepressant Exposure and Likely Gene Disrupting Mutations on the Severity of Autism Spectrum Disorder[J]. J Autism Dev Disord, 2017, 47(11): 3489-3496.

28. Sujan A C, Rickert M E, Oberg A S, et al. Associations of Maternal Antidepressant Use During the First Trimester of Pregnancy With Preterm Birth, Small for Gestational Age, Autism Spectrum Disorder, and Attention-Deficit/Hyperactivity Disorder in Offspring[J]. JAMA, 2017, 317(15): 1553-1562.

29. Malm H, Brown A S, Gissler M, et al. Gestational Exposure to Selective Serotonin Reuptake Inhibitors and Offspring Psychiatric Disorders: A National Register-Based Study[J]. J Am Acad Child Adolesc Psychiatry, 2016, 55(5): 359-366.

30. Lupattelli A, Wood M, Ystrom E, et al. Effect of Time-Dependent Selective Serotonin Reuptake Inhibitor Antidepressants During Pregnancy on Behavioral, Emotional, and Social Development in Preschool-Aged Children[J]. J Am Acad Child Adolesc Psychiatry, 2018, 57(3): 200-208.

31. Oberlander T F, Gingrich J A, Ansorge M S. Sustained neurobehavioral effects of exposure to SSRI antidepressants during development: molecular to clinical evidence[J]. Clin Pharmacol Ther, 2009, 86(6): 672-677.

32. Miyazaki K, Narita N, Narita M. Maternal administration of thalidomide or valproic acid causes abnormal serotonergic neurons in the offspring: implication for pathogenesis of autism[J]. Int $\mathrm{J}$ Dev Neurosci, 2005, 23(2-3): 287-297.

33. Logue S F, Gould T J. The neural and genetic basis of executive function: attention, cognitive flexibility, and response inhibition[J]. Pharmacol Biochem Behav, 2014, 123: 45-54.

34. Salas C E, Radovic D, Yuen K S, et al. "Opening an emotional dimension in me": changes in emotional reactivity and emotion regulation in a case of executive impairment after left fronto-parietal damage[J]. Bull Menninger Clin, 2014, 78(4): 301-334. 
35. Devito T J, Drost D J, Neufeld R W, et al. Evidence for cortical dysfunction in autism: a proton magnetic resonance spectroscopic imaging study[J]. Biol Psychiatry, 2007, 61(4): 465-473.

36. Libero L E, Deramus T P, Lahti A C, et al. Multimodal neuroimaging based classification of autism spectrum disorder using anatomical, neurochemical, and white matter correlates[J]. Cortex, 2015, 66: 4659.

37. Olivier J D, Valles A, van Heesch F, et al. Fluoxetine administration to pregnant rats increases anxietyrelated behavior in the offspring[J]. Psychopharmacology (Berl), 2011, 217(3): 419-432.

38. Kroeze Y, Dirven B, Janssen S, et al. Perinatal reduction of functional serotonin transporters results in developmental delay[J]. Neuropharmacology, 2016, 109: 96-111.

39. Dufour-Rainfray D, Vourc'H P, Le Guisquet A M, et al. Behavior and serotonergic disorders in rats exposed prenatally to valproate: a model for autism[J]. Neurosci Lett, 2010, 470(1): 55-59.

40. Shahrokhi A, Hassanzadeh G, Vousooghi N, et al. The effect of tiagabine on physical development and neurological reflexes and their relationship with the gamma-aminobutyric acid switch in the rat cerebral cortex during developmental stages[J]. Behav Pharmacol, 2013, 24(7): 561-568.

41. Altman J, Sudarshan K. Postnatal development of locomotion in the laboratory rat[J]. Anim Behav, 1975, 23(4): 896-920.

42. Edwards D A, Thompson M L, Burge K G. Olfactory bulb removal vs peripherally induced anosmia: differential effects on the aggressive behavior of male mice[J]. Behav Biol, 1972, 7(6): 823-828.

43. Nathan B P, Yost J, Litherland M T, et al. Olfactory function in apoE knockout mice[J]. Behav Brain Res, 2004, 150(1-2): 1-7.

44. Lu D C, Zhang H, Zador Z, et al. Impaired olfaction in mice lacking aquaporin-4 water channels[J]. FASEB J, 2008, 22(9): 3216-3223.

45. Pahkla R, Harro J, Rago L. Behavioural effects of pinoline in the rat forced swimming, open field and elevated plus-maze tests[J]. Pharmacol Res, 1996, 34(1-2): 73-78.

46. Nadler J J, Moy S S, Dold G, et al. Automated apparatus for quantitation of social approach behaviors in mice[J]. Genes, Brain and Behavior, 2004, 3(5): 303-314.

47. Li Q, Wong J H, Lu G, et al. Gene expression of synaptosomal-associated protein 25 (SNAP-25) in the prefrontal cortex of the spontaneously hypertensive rat (SHR)[J]. Biochim Biophys Acta, 2009, 1792(8): 766-776.

48. Li Q, Leung Y O, Zhou I, et al. Dietary supplementation with n-3 fatty acids from weaning limits brain biochemistry and behavioural changes elicited by prenatal exposure to maternal inflammation in the mouse model[J]. Transl Psychiatry, 2015, 5: e641.

49. Schwarz A J, Danckaert A, Reese T, et al. A stereotaxic MRI template set for the rat brain with tissue class distribution maps and co-registered anatomical atlas: application to pharmacological MRI[J]. Neuroimage, 2006, 32(2): 538-550.

50.Zhang H, Huang M, Gao L, et al. Region-specific cerebral metabolic alterations in streptozotocininduced type 1 diabetic rats: an in vivo proton magnetic resonance spectroscopy study[J]. J Cereb Blood Flow Metab, 2015, 35(11): 1738-1745.

51. Li S, Wang X, Yang J, et al. Metabolic profile of visual cortex in diabetic rats measured with in vivo proton MRS[J]. NMR Biomed, 2017, 30(11). 
52. Li Q, Leung Y O, Zhou I, et al. Dietary supplementation with n-3 fatty acids from weaning limits brain biochemistry and behavioural changes elicited by prenatal exposure to maternal inflammation in the mouse model[J]. Transl Psychiatry, 2015, 5: e641.

53. Katayama H, Nagasu T, Oda Y. Improvement of in-gel digestion protocol for peptide mass fingerprinting by matrix-assisted laser desorption/ionization time-of-flight mass spectrometry[J]. Rapid Commun Mass Spectrom, 2001, 15(16): 1416-1421.

54. Deng M Y, Lam S, Meyer U, et al. Frontal-subcortical protein expression following prenatal exposure to maternal inflammation[J]. PLoS One, 2011, 6(2): e16638.

55.Tischfield M A, Baris H N, Wu C, et al. Human TUBB3 mutations perturb microtubule dynamics, kinesin interactions, and axon guidance[J]. Cell, 2010, 140(1): 74-87.

56.Rosner M, Hengstschlager M. 14-3-3 proteins are involved in the regulation of mammalian cell proliferation[J]. Amino Acids, 2006, 30(1): 105-109.

57.Wang L H, Strittmatter S M. A family of rat CRMP genes is differentially expressed in the nervous system[J]. J Neurosci, 1996, 16(19): 6197-6207.

58.Rostovtseva T K, Tan W, Colombini M. On the role of VDAC in apoptosis: fact and fiction[J]. J Bioenerg Biomembr, 2005, 37(3): 129-142.

59. Hernanz A, de la Fuente M. Characterization of aconitate hydratase from mitochondria and cytoplasm of ascites tumor cells[J]. Biochem Cell Biol, 1988, 66(7): 792-795.

60. Tochio T, Tanaka H, Nakata S, et al. Fructose-1,6-bisphosphate aldolase A is involved in HaCaT cell migration by inducing lamellipodia formation[J]. J Dermatol Sci, 2010, 58(2): 123-129.

61.Coe H, Schneider J D, Dabrowska M, et al. Role of cysteine amino acid residues in calnexin[J]. Mol Cell Biochem, 2012, 359(1-2): 271-281.

62. Park J E, Lee $D H$, Lee $J$ A, et al. Annexin A3 is a potential angiogenic mediator[J]. Biochem Biophys Res Commun, 2005, 337(4): 1283-1287.

63.Recktenwald C V, Kellner R, Lichtenfels R, et al. Altered detoxification status and increased resistance to oxidative stress by K-ras transformation[J]. Cancer Res, 2008, 68(24): 10086-10093.

64. Tai H C, Schuman E M. Ubiquitin, the proteasome and protein degradation in neuronal function and dysfunction[J]. Nat Rev Neurosci, 2008, 9(11): 826-838.

65. Cox A G, Winterbourn C C, Hampton M B. Mitochondrial peroxiredoxin involvement in antioxidant defence and redox signalling[J]. Biochem J, 2009, 425(2): 313-325.

66. Bairy K L, Madhyastha S, Ashok K P, et al. Developmental and behavioral consequences of prenatal fluoxetine[J]. Pharmacology, 2007, 79(1): 1-11.

67. Deiro T C, Carvalho J, Nascimento E, et al. Neonatal exposure to citalopram, a serotonin selective reuptake inhibitor, programs a delay in the reflex ontogeny in rats[J]. Arq Neuropsiquiatr, 2008, 66(3B): 736-740.

68. Bolivar V J. Intrasession and intersession habituation in mice: from inbred strain variability to linkage analysis[J]. Neurobiol Learn Mem, 2009, 92(2): 206-214.

69. Prut $L$, Belzung $C$. The open field as a paradigm to measure the effects of drugs on anxiety-like behaviors: a review[J]. Eur J Pharmacol, 2003, 463(1-3): 3-33.

70. Smit-Rigter L A, Noorlander C W, von Oerthel L, et al. Prenatal fluoxetine exposure induces life-long 
serotonin 5-HT(3) receptor-dependent cortical abnormalities and anxiety-like behaviour[J]. Neuropharmacology, 2012, 62(2): 865-870.

71. Rebello T J, Yu Q, Goodfellow N M, et al. Postnatal day 2 to 11 constitutes a 5-HT-sensitive period impacting adult mPFC function[J]. J Neurosci, 2014, 34(37): 12379-12393.

72.Ansorge M S, Zhou M, Lira A, et al. Early-life blockade of the 5-HT transporter alters emotional behavior in adult mice[J]. Science, 2004, 306(5697): 879-881.

73. Lee $L \mathrm{~J}$, Lee $L \mathrm{~J}$. Neonatal fluoxetine exposure alters motor performances of adolescent rats[J]. Dev Neurobiol, 2012, 72(8): 1122-1132.

74.Zheng J, Xu D F, Li K, et al. Neonatal exposure to fluoxetine and fluvoxamine alteres spine density in mouse hippocampal CA1 pyramidal neurons[J]. Int J Clin Exp Pathol, 2011, 4(2): 162-168.

75. Nagano $\mathrm{M}$, Liu M, Inagaki $\mathrm{H}$, et al. Early intervention with fluoxetine reverses abnormalities in the serotonergic system and behavior of rats exposed prenatally to dexamethasone[J]. Neuropharmacology, 2012, 63(2): 292-300.

76.Rodriguez-Porcel F, Green D, Khatri N, et al. Neonatal exposure of rats to antidepressants affects behavioral reactions to novelty and social interactions in a manner analogous to autistic spectrum disorders[J]. Anat Rec (Hoboken), 2011, 294(10): 1726-1735.

77. Maciag D, Simpson K L, Coppinger D, et al. Neonatal antidepressant exposure has lasting effects on behavior and serotonin circuitry[J]. Neuropsychopharmacology, 2006, 31(1): 47-57.

78. Clayton A H, El H S, lluonakhamhe J P, et al. Sexual dysfunction associated with major depressive disorder and antidepressant treatment[J]. Expert Opin Drug Saf, 2014, 13(10): 1361-1374.

79. Montgomery S A, Baldwin D S, Riley A. Antidepressant medications: a review of the evidence for druginduced sexual dysfunction[J]. J Affect Disord, 2002, 69(1-3): 119-140.

80. Clayton A H, Pradko J F, Croft H A, et al. Prevalence of sexual dysfunction among newer antidepressants[J]. J Clin Psychiatry, 2002, 63(4): 357-366.

81 Rai D, Lee B K, Dalman C, et al. Antidepressants during pregnancy and autism in offspring: population based cohort study[J]. BMJ, 2017, 358: j2811.

82 Kaplan Y C, Keskin-Arslan E, Acar S, et al. Prenatal selective serotonin reuptake inhibitor use and the risk of autism spectrum disorder in children: A systematic review and meta-analysis[J]. Reprod Toxicol, 2016, 66: 31-43.

83.Schoenichen C, Bode C, Duerschmied D. Role of platelet serotonin in innate immune cell recruitment[J]. Front Biosci (Landmark Ed), 2019, 24: 514-526.

84. Chugani D C. Role of altered brain serotonin mechanisms in autism[J]. Mol Psychiatry, 2002, 7 Suppl 2: S16-S17.

85.Makkonen I, Riikonen R, Kokki H, et al. Serotonin and dopamine transporter binding in children with autism determined by SPECT[J]. Dev Med Child Neurol, 2008, 50(8): 593-597.

86.Li X, Zou H, Brown W T. Genes associated with autism spectrum disorder[J]. Brain Res Bull, 2012, 88(6): 543-552.

87. Yang M S, Gill M. A review of gene linkage, association and expression studies in autism and an assessment of convergent evidence[J]. Int J Dev Neurosci, 2007, 25(2): 69-85.

88.Lira A, Zhou M, Castanon N, et al. Altered depression-related behaviors and functional changes in the 
dorsal raphe nucleus of serotonin transporter-deficient mice[J]. Biol Psychiatry, 2003, 54(10): 960-971. 89.Klomp A, Vaclavu L, Meerhoff G F, et al. Effects of chronic fluoxetine treatment on neurogenesis and tryptophan hydroxylase expression in adolescent and adult rats[J]. PLoS One, 2014, 9(5): e97603. 90. Baik S Y, Jung K H, Choi M R, et al. Fluoxetine-induced up-regulation of 14-3-3zeta and tryptophan hydroxylase levels in RBL-2H3 cells[J]. Neurosci Lett, 2005, 374(1): 53-57.

91. Simpson K L, Weaver K J, de Villers-Sidani E, et al. Perinatal antidepressant exposure alters cortical network function in rodents[J]. Proc Natl Acad Sci U S A, 2011, 108(45): 18465-18470.

92. Baslow M H. Evidence that the tri-cellular metabolism of $\mathrm{N}$-acetylaspartate functions as the brain's "operating system": how NAA metabolism supports meaningful intercellular frequency-encoded communications[J]. Amino Acids, 2010, 39(5): 1139-1145.

93.Walecki J, Barcikowska M, Cwikla J B, et al. N-acetylaspartate, choline, myoinositol, glutamine and glutamate (glx) concentration changes in proton MR spectroscopy (1H MRS) in patients with mild cognitive impairment (MCl)[J]. Med Sci Monit, 2011, 17(12): T105-T111.

94. Fujii E, Mori K, Miyazaki M, et al. Function of the frontal lobe in autistic individuals: a proton magnetic resonance spectroscopic study[J]. J Med Invest, 2010, 57(1-2): 35-44.

95.Mori K, Toda $\mathrm{Y}$, Ito $\mathrm{H}$, et al. A proton magnetic resonance spectroscopic study in autism spectrum disorders: amygdala and orbito-frontal cortex[J]. Brain Dev, 2013, 35(2): 139-145.

96. Horder J, Lavender T, Mendez M A, et al. Reduced subcortical glutamate/glutamine in adults with autism spectrum disorders: a [(1)H]MRS study[J]. Transl Psychiatry, 2014, 4: e364.

97.Wang Z, Li W, Chen J, et al. Proteomic analysis reveals energy metabolic dysfunction and neurogenesis in the prefrontal cortex of a lipopolysaccharide-induced mouse model of depression[J]. Mol Med Rep, 2016, 13(2): 1813-1820.

98. Gellen B, Volgyi K, Gyorffy B A, et al. Proteomic investigation of the prefrontal cortex in the rat clomipramine model of depression[J]. J Proteomics, 2017, 153: 53-64.

99.Rose S, Melnyk S, Pavliv O, et al. Evidence of oxidative damage and inflammation associated with low glutathione redox status in the autism brain[J]. Transl Psychiatry, 2012, 2: e134.

100. Focking M, Lopez L M, English J A, et al. Proteomic and genomic evidence implicates the postsynaptic density in schizophrenia[J]. Mol Psychiatry, 2015, 20(4): 424-432.

101.Aitken A. 14-3-3 proteins: a historic overview[J]. Semin Cancer Biol, 2006, 16(3): 162-172.

102. Bruno D L, Anderlid B M, Lindstrand A, et al. Further molecular and clinical delineation of co-locating 17p13.3 microdeletions and microduplications that show distinctive phenotypes[J]. J Med Genet, 2010, 47(5): 299-311.

103. Fromer M, Pocklington A J, Kavanagh D H, et al. De novo mutations in schizophrenia implicate synaptic networks[J]. Nature, 2014, 506(7487): 179-184.

104. Wong A H, Likhodi O, Trakalo J, et al. Genetic and post-mortem mRNA analysis of the 14-3-3 genes that encode phosphoserine/threonine-binding regulatory proteins in schizophrenia and bipolar disorder[J]. Schizophr Res, 2005, 78(2-3): 137-146.

105. Grover D, Verma R, Goes F S, et al. Family-based association of YWHAH in psychotic bipolar disorder[J]. Am J Med Genet B Neuropsychiatr Genet, 2009, 150B(7): 977-983.

106. Pagan C, Goubran-Botros H, Delorme R, et al. Disruption of melatonin synthesis is associated with 
impaired 14-3-3 and miR-451 levels in patients with autism spectrum disorders[J]. Sci Rep, 2017, 7(1): 2096.

107. Pagan C, Delorme R, Callebert J, et al. The serotonin-N-acetylserotonin-melatonin pathway as a biomarker for autism spectrum disorders[J]. Transl Psychiatry, 2014, 4: e479.

108. Cheah P S, Ramshaw H S, Thomas P Q, et al. Neurodevelopmental and neuropsychiatric behaviour defects arise from 14-3-3zeta deficiency[J]. Mol Psychiatry, 2012, 17(4): 451-466.

109. Xu X, Jaehne E J, Greenberg Z, et al. 14-3-3zeta deficient mice in the BALB/c background display behavioural and anatomical defects associated with neurodevelopmental disorders[J]. Sci Rep, 2015, 5: 12434.

110.Dimatelis J J, Stein D J, Russell V A. Chronic exposure to light reverses the effect of maternal separation on proteins in the prefrontal cortex[J]. J Mol Neurosci, 2013, 51(3): 835-843.

111.Glombik K, Stachowicz A, Trojan E, et al. Evaluation of the effectiveness of chronic antidepressant drug treatments in the hippocampal mitochondria - A proteomic study in an animal model of depression[J]. Prog Neuropsychopharmacol Biol Psychiatry, 2017, 78: 51-60.

112. Yamashita N, Goshima Y. Collapsin response mediator proteins regulate neuronal development and plasticity by switching their phosphorylation status[J]. Mol Neurobiol, 2012, 45(2): 234-246.

113.Chen $\mathrm{Y}$, Sheng $\mathrm{H}, \mathrm{Xu} \mathrm{Y}$, et al. Activation of CRHR2 exerts an inhibitory effect on the expression of collapsin response mediator protein 3 in hippocampal neurons[J]. Neuropeptides, 2012, 46(2): 93-98.

114.Tsim T Y, Wong E Y, Leung M S, et al. Expression of axon guidance molecules and their related genes during development and sexual differentiation of the olfactory bulb in rats[J]. Neuroscience, 2004, 123(4): 951-965.

115.Quach T T, Massicotte G, Belin M F, et al. CRMP3 is required for hippocampal CA1 dendritic organization and plasticity[J]. FASEB J, 2008, 22(2): 401-409.

116. Nacher J, Soriano S, Varea E, et al. CRMP-4 expression in the adult cerebral cortex and other telencephalic areas of the lizard Podarcis hispanica[J]. Brain Res Dev Brain Res, 2002, 139(2): 285-294. 117. Tsutiya A, Nakano Y, Hansen-Kiss E, et al. Human CRMP4 mutation and disrupted Crmp4 expression in mice are associated with ASD characteristics and sexual dimorphism[J]. Sci Rep, 2017, 7(1): 16812. 118.Parker W, Hornik C D, Bilbo S, et al. The role of oxidative stress, inflammation and acetaminophen exposure from birth to early childhood in the induction of autism[J]. J Int Med Res, 2017, 45(2): 407-438. 119.Khongrum J, Wattanathorn J. Laser Acupuncture Improves Behavioral Disorders and Brain Oxidative Stress Status in the Valproic Acid Rat Model of Autism[J]. J Acupunct Meridian Stud, 2015, 8(4): 183-191. 120.Faber S, Zinn G M, Boggess A, et al. A cleanroom sleeping environment's impact on markers of oxidative stress, immune dysregulation, and behavior in children with autism spectrum disorders[J]. BMC Complement Altern Med, 2015, 15: 71.

121.Al-Amin M M, Rahman M M, Khan F R, et al. Astaxanthin improves behavioral disorder and oxidative stress in prenatal valproic acid-induced mice model of autism[J]. Behav Brain Res, 2015, 286: 112-121. 122. Martin H L, Teismann P. Glutathione--a review on its role and significance in Parkinson's disease[J]. FASEB J, 2009, 23(10): 3263-3272.

123.Butterfield D A, Drake J, Pocernich C, et al. Evidence of oxidative damage in Alzheimer's disease brain: central role for amyloid beta-peptide[J]. Trends Mol Med, 2001, 7(12): 548-554. 
124.Yao J K, Leonard S, Reddy R. Altered glutathione redox state in schizophrenia[J]. Dis Markers, 2006, 22(1-2): 83-93.

125.Andreazza A C, Kauer-Sant'Anna M, Frey B N, et al. Oxidative stress markers in bipolar disorder: a meta-analysis[J]. J Affect Disord, 2008, 111(2-3): 135-144.

\section{Figures}

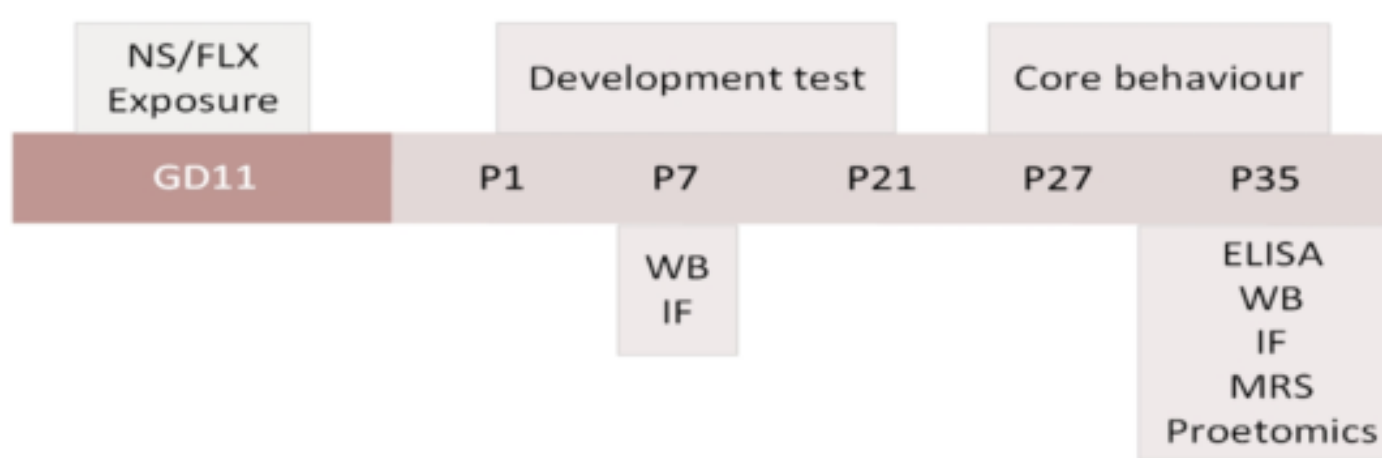

\section{Figure 1}

Flow diagram of experiment. Dams were exposed to fluoxetine (FLX) or normal saline (NS) beginning at gestational day (GD) 11 throughout pregnancy. Developmental tests were measured in lactation period in offspring. The core behaviors of buried food pellet test, open field test and social behavior were performed in adolescent offspring. The 5-HT level were measured at postnatal days (PND) 35 using ELISA assay, while TPH and SERT expression at PND 7 and 35 were detected by western blot and immunofluorescence (IF) technique. MRS and proteomics were implemented at PND 35. 

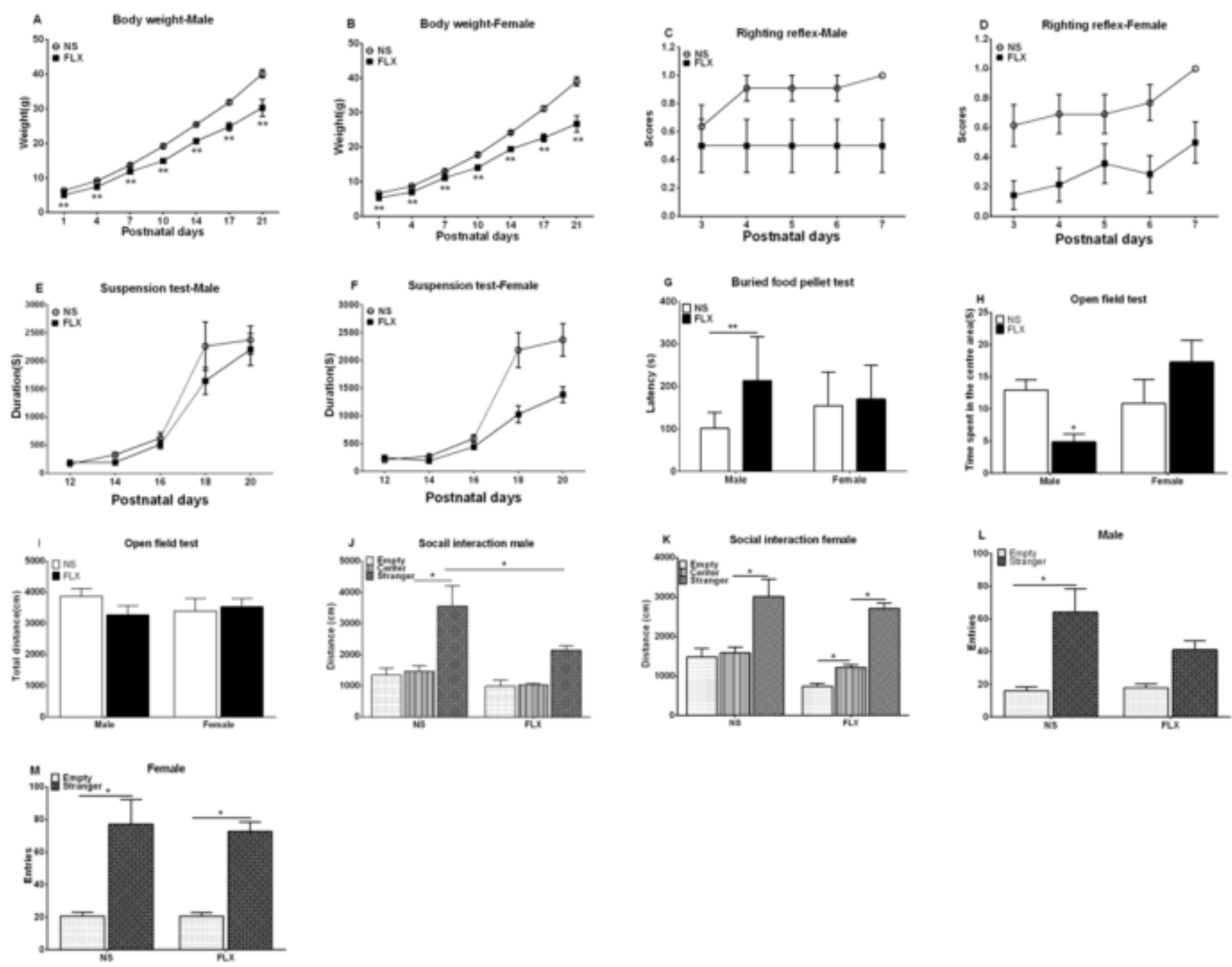

\section{Figure 2}

Effect of prenatal FLX exposure on body weight in male (A) and female (B) offspring. Effect of prenatal FLX exposure on the righting reflex in male (C) and female (D) offspring. Effect of prenatal FLX exposure on the suspension test in male $(E)$ and female $(F)$ offspring. Effect of prenatal FLX exposure in the buried food pellet test in male and female offspring $(G)$ Effect of prenatal FLX exposure on the open field test in male and female offspring. $(\mathrm{H})$ time spent in the centre areas in male and female rats. $(\mathrm{I})$ total distances moved in specific areas in male and female rats. Effect of prenatal FLX exposure on the sociability test in male and female offspring. $(\mathrm{J})$ the initiation of social interaction by male offspring; $(\mathrm{K})$ the initiation of social interaction by female offspring; $(\mathrm{L})$ locomotor activity during the sociability test in male offspring; (M) locomotor activity during the sociability test in female offspring. Data are presented as Mean \pm S.E.M. ${ }^{*} p<0.05, \# p<0.01$. NS, prenatal exposure to normal saline; $F L X$, prenatal exposure to fluoxetine. 

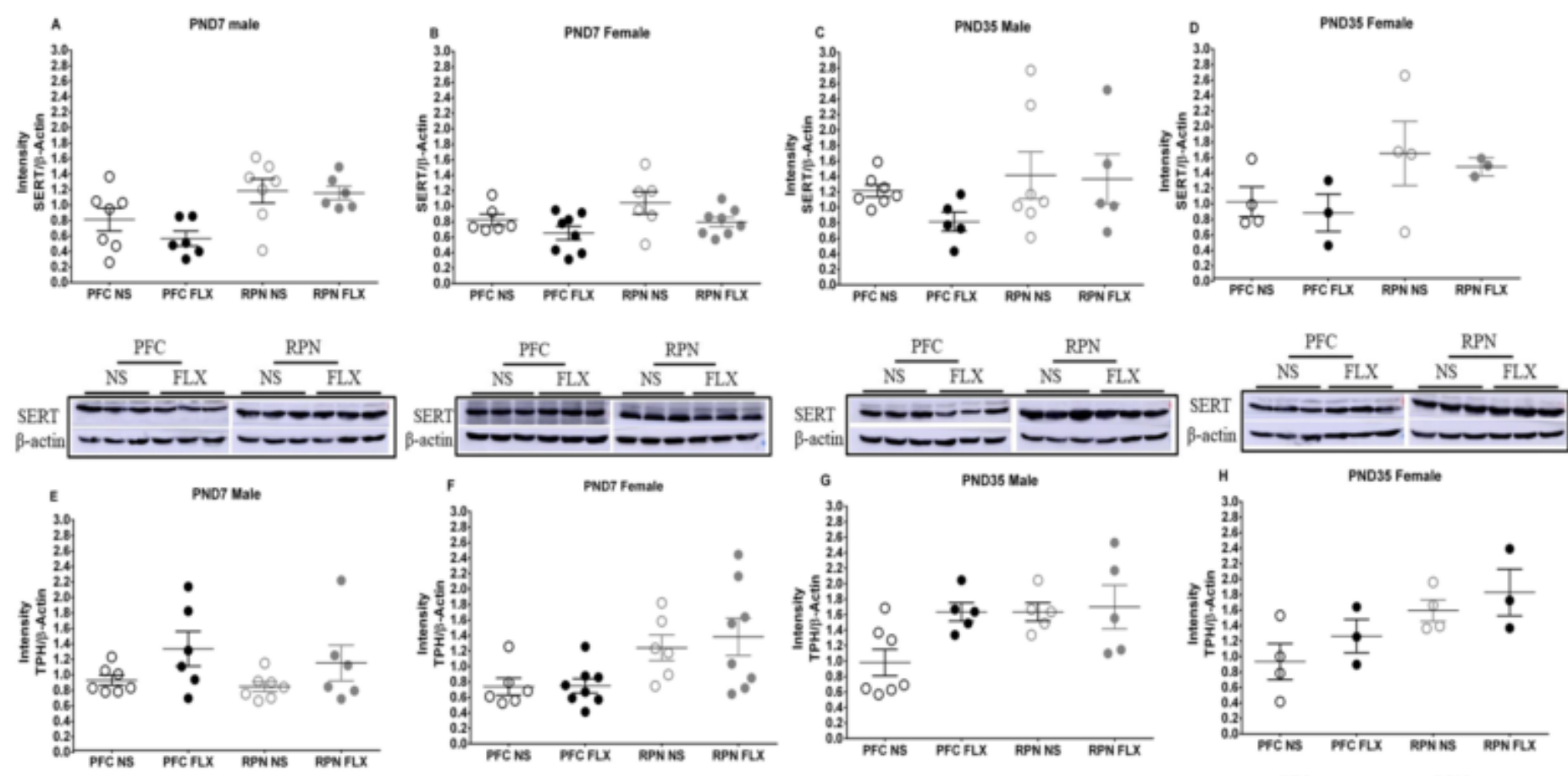

$$
\frac{\text { PFC }}{N S \quad F L X} \quad \frac{\text { RPN }}{N S \text { FLX }}
$$

$\stackrel{\text { PFC }}{\text { NS }} \frac{\text { RPX }}{\text { NS FLX }}$

$\frac{\mathrm{PFC}}{\mathrm{NS}} \stackrel{\mathrm{FLX}}{\mathrm{NPN}} \frac{\mathrm{FLX}}{\mathrm{NS}}$

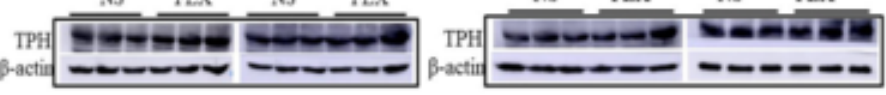

Figure 3

Effect of prenatal FLX exposure on SERT expression in PFC and RPN in male (A) and female (B) offspring at PND 7; in male (C) and female (D) offspring at PND 35. Effect of prenatal FLX exposure on TPH expression in the PFC and RPN in male (E) and female (F) offspring at PND 7; in male (G) and female (H) offspring at PND 35. All values represented Mean \pm S.E.M. ${ }^{*} p<0.05$. NS, prenatal exposure to normal saline; FLX, prenatal exposure to fluoxetine. PFC, prefrontal cortex; RPN, raphe nucleus.

A

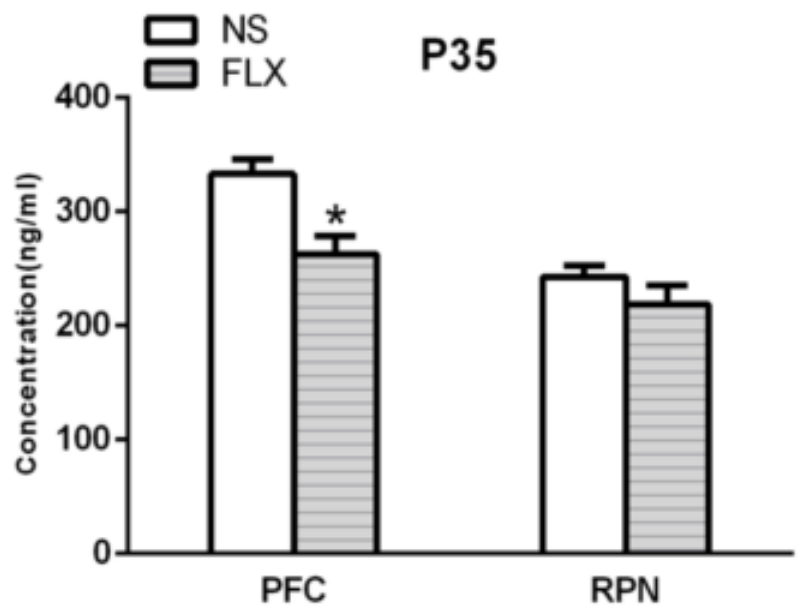

Male
$\mathrm{B}$

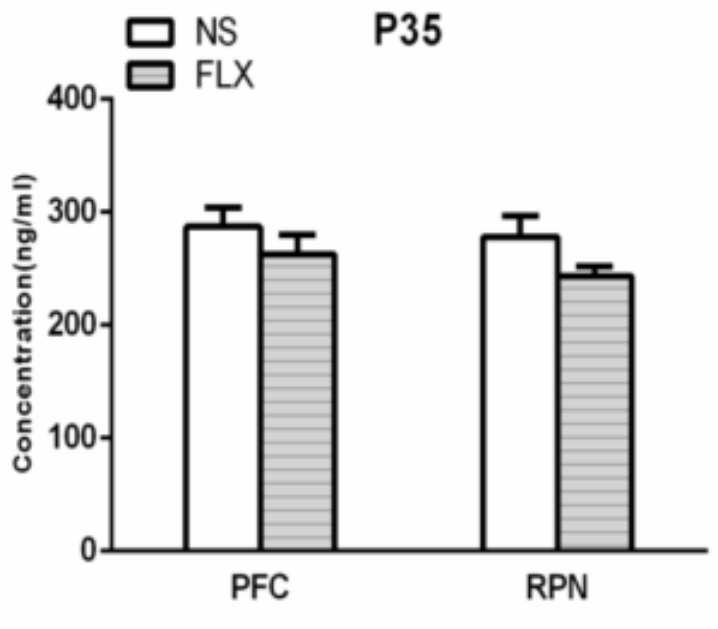

Female 


\section{Figure 4}

Effect of prenatal FLX exposure on 5-HT levels (ng/ml) in PFC and PRN (PND 35) in male (A) and female (B) offspring. Results are expressed as Mean \pm S.E.M. * $p<0.05$. NS, prenatal exposure to normal saline; FLX, prenatal exposure to fluoxetine. PFC, prefrontal cortex; RPN, raphe nucleus.

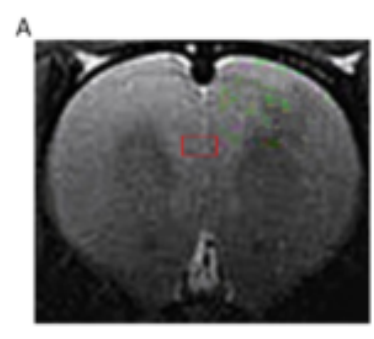

c
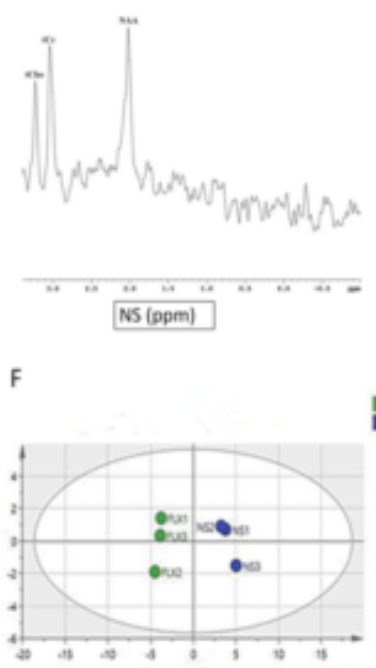
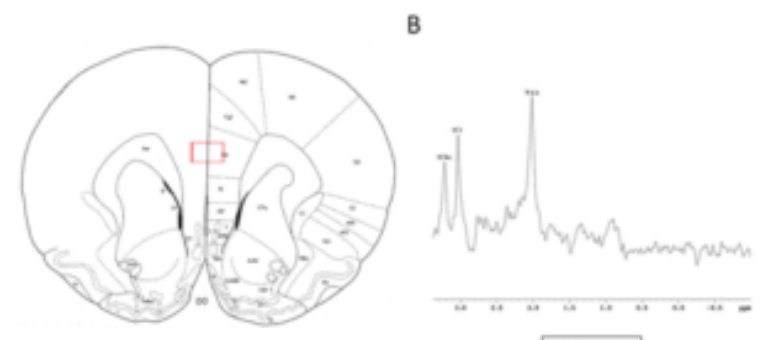

NS (ppm)
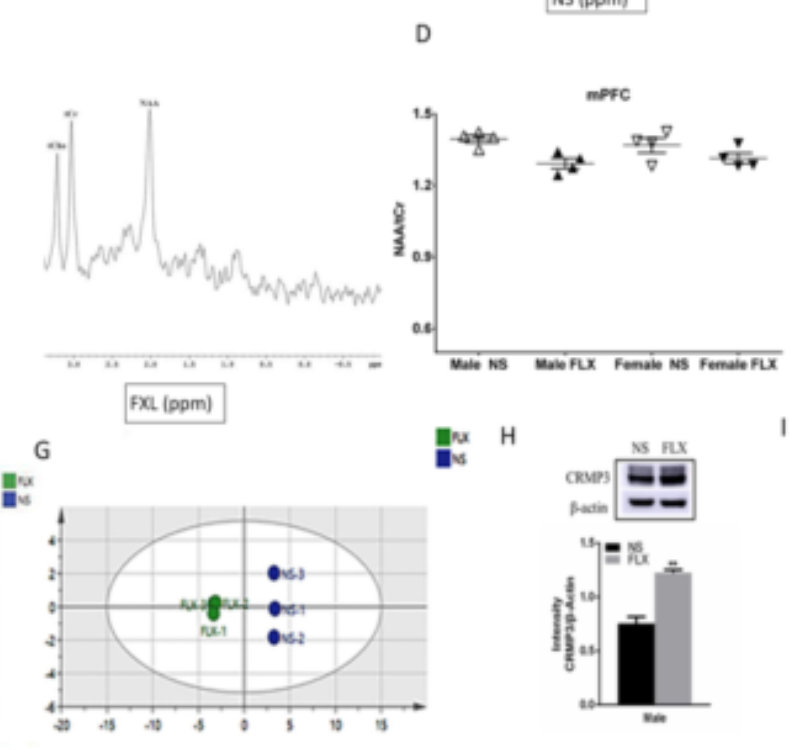

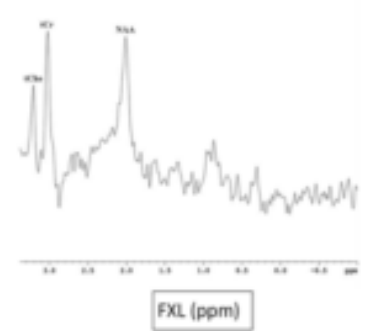

E

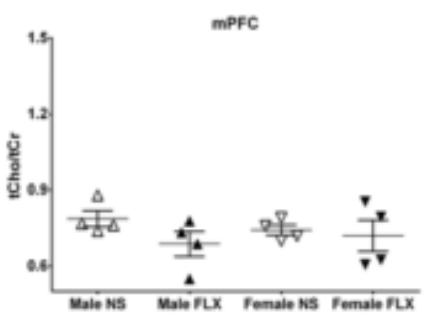

I

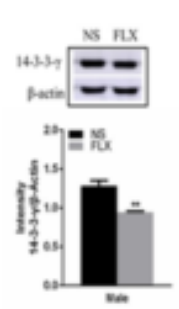

\section{Figure 5}

Representative MRS voxel-of-interest in the MPFC and MRS metabolite levels in male and female offspring at PND 35 prenatal exposed to FLX and NS. (A) Voxel-of-interest with the size of $2 \times 2.5 \times 2.4$ $\mathrm{mm} 3$ was positioned in the medial prefrontal cortex of the male and female offspring. The rat atlas reference for the MPFC is from the Allen Institute; (B) Representative in vivo $1 \mathrm{H}$ spectra with quantum estimation (QUEST) fitting from the medial prefrontal cortex in male.(C)Representative in vivo $1 \mathrm{H}$ spectra with quantum estimation (QUEST) fitting from the medial prefrontal cortex in female. (D) $\mathrm{N}$ acetylaspartate (NAA)/total creatine $(\mathrm{tCr})$ in prenatal FLX-exposured group compared with NS-exposured group of both sexes. (E) total choline (tCho)/total creatine (tCr) in prenatal FLX-exposured group compared with NS-exposured group of both sexes. Multivariate analysis of proteomic experiment: partial least squares-discriminative analysis (PLS-DA) carried out using SIMCA-P+12.0 software (Umetrics). The prefrontal cortex protein profile following FLX exposure could be differentiated from the expression of saline (controls) exposure in males (F) and in females (G). The XY axis shows the coordinates of the protein distribution in the partial least squares discriminative analysis. $(\mathrm{H})$ CRMP3 protein level in the PFC in male offspring. (I) 14-3-3-4 protein level in the PFC in males. (J) Peroxiredoxin 3 protein level in PFC in 
female offspring. Results are expressed as Mean \pm S.E.M. ${ }^{\star} p<0.05,{ }^{\star \star} p<0.01$. NS, prenatal exposure to normal saline; FLX, prenatal exposure to fluoxetine. PFC, prefrontal cortex.

\section{Supplementary Files}

This is a list of supplementary files associated with this preprint. Click to download.

- Supplementalfile.docx 